\title{
Suhuai suckling piglet hindgut microbiome-metabolome responses to different dietary copper levels
}

\author{
Feng Zhang ${ }^{1,2} \cdot$ Weijiang Zheng ${ }^{1} \cdot$ Yongqiang Xue ${ }^{1} \cdot$ Wen Yao ${ }^{1,3}$
}

Received: 24 July 2018 / Revised: 7 November 2018 / Accepted: 18 November 2018 / Published online: 7 December 2018

(C) The Author(s) 2018

\begin{abstract}
Unabsorbed copper accumulates in the hindgut of pigs that consume high levels of dietary copper, which enhances the coselection of antibiotic-resistant bacteria and is considered detrimental to the environment and to porcine health. In our study, a combination of $16 \mathrm{~S}$ rRNA pyrosequencing and nontargeted metabolomics was used to investigate the microbiome-metabolome responses to dietary copper levels in the hindgut of suckling piglets. The results showed that the dietary copper level affected the abundance of several Clostridia genera and that the relative abundance of butyrate-producing bacteria, such as Coprococcus, Roseburia, and Acidaminococcus, was reduced in the $300 \mathrm{mg} \mathrm{kg}^{-1}$ (high) $\mathrm{Cu}$ group. Metabolomic analysis revealed that dietary copper levels affected protein and carbohydrate metabolites, protein biosynthesis, the urea cycle, galactose metabolism, gluconeogenesis, and amino acid metabolism (including the metabolism of arginine, proline, $\beta$-alanine, phenylalanine, tyrosine, and methionine). Furthermore, Pearson's correlation analysis showed that the abundance levels of Coprococcus (family Lachnospiraceae) and operational taxonomic unit (OTU) 18 (family Ruminococcaceae) were positively correlated with energy metabolism pathways (gluconeogenesis, glycolysis, and the pentose phosphate pathway). The abundance of Streptococcus was negatively correlated with amino acid metabolism pathways (protein biosynthesis, glycine, serine, threonine, methionine, phenylalanine, and tyrosine metabolism), and OTU583 and OTU1067 (family Rikenellaceae) were positively correlated with amino acid metabolism pathways. These results suggest that the copper levels consumed by LC (low-copper group) versus HC (highcopper group) animals alter the composition of the gut microbiota and modulate microbial metabolic pathways, which may further affect the health of suckling piglets.
\end{abstract}

Keywords Piglet $\cdot$ Microbiota $\cdot$ Metabolite profiles $\cdot$ Copper $\cdot$ Hindgut

\section{Introduction}

Copper is an essential microelement for life, and copper toxicity can occur in any species, including ruminants and monogastric animals, that consumes excessive amounts of

Electronic supplementary material The online version of this article (https://doi.org/10.1007/s00253-018-9533-0) contains supplementary material, which is available to authorized users.

Wen Yao

yaowen67jp@njau.edu.cn

1 Jiangsu Key Laboratory of Gastrointestinal Nutrition and Animal Health, College of Animal Science and Technology, Nanjing Agricultural University, Nanjing, China

2 College of Agriculture, Guangdong Ocean University, Zhanjiang, China

3 Key Lab of Animal Physiology and Biochemistry, Ministry of Agriculture, Nanjing, China supplemental copper. When ruminants consume too much copper, they accumulate copper in the liver before the toxicity becomes apparent. Stress or other factors can cause a large amount of copper to be suddenly released from the liver into the blood, leading to a hemolytic crisis. This type of crisis is characterized by considerable hemolysis, jaundice, methemoglobinemia, hemoglobinuria, systemic jaundice, extensive necrosis, and frequent death (Goff 2004; Puig and Thiele 2002; Scheiber et al. 2014). However, ruminants are much more susceptible than monogastric animals. Pigs can tolerate more than $250 \mathrm{mg} \mathrm{kg}^{-1}$ copper in their diet, and dietary copper at a level of 100 to $250 \mathrm{mg} \mathrm{kg}^{-1}$ has been widely reported to promote growth and increase the feed intake and growth performance of pigs (Armstrong et al. 2004; Fry et al. 2012; Huang et al. 2015; Lu et al. 2010; Zhou et al. 1994); $250 \mathrm{mg} \mathrm{kg}^{-1}$ dietary copper was considered the most efficacious level in nursery pigs (Ma et al. 2015). Therefore, feed is generally supplemented with a high concentration of copper in China's swine industry. 
In addition, many studies reported that dietary high levels of copper, used as an alternative to antibiotic growth promoters in animal production, might further enhance the coselection of antibiotic-resistant bacteria (Baker-Austin et al. 2006; Brown et al. 1992; Hasman and Aarestrup 2002; Hölzel et al. 2012; Seiler and Berendonk 2012). Excess copper in feed is considered to be detrimental to the environment via excretion whether or not the animal absorbs the copper (Armstrong et al. 2004; Jondreville et al. 2003; Veum et al. 2004). Thus, the question of whether excess supplementation of $\mathrm{Cu}$ in feed affects pig health is gaining renewed attention.

Our previous studies showed that high levels of copper in the diet lead to a major accumulation of unabsorbed copper in rat feces, which affects microbial composition by altering the populations of certain bacteria (Zhang et al. 2017a). The effect of dietary copper level on the gut microbiota of pigs is also complex and changeable. The addition of either bound (36 to $\left.47 \mathrm{mg} \mathrm{kg}^{-1}, \mathrm{Cu}-\mathrm{montmorillonite}\right)$ or inorganic $\left(200 \mathrm{mg} \mathrm{kg}^{-1}\right.$, $\mathrm{CuSO}_{4} / \mathrm{CuO}$ ) copper has been reported to decrease the Clostridium population in piglets and growing pigs (Song et al. 2013; Xia et al. 2005). Dietary copper $>100 \mathrm{mg} \mathrm{kg}^{-1}$ $\left(\mathrm{CuSO}_{4}\right)$ has been shown to reduce the Streptococcus population in the porcine gut but does not appear to have any effect on the coliform bacteria population (Bunch et al. 1961; Hawbaker et al. 1961; Hojberg et al. 2005; Kellogg et al. 1966; Mei et al. 2010; Namkung et al. 2006; Varel et al. 1987). Supplementation of $>170 \mathrm{mg} \mathrm{kg}^{-1}$ copper $\left(\mathrm{CuSO}_{4}\right)$ in diets reduced Enterococcus and lactic acid bacteria populations in the stomach content, as well as Lactobacillus in the gastrointestinal tract of pigs; however, $\mathrm{Cu}$ in the form of $\mathrm{CuO}$ did not have the same effect (Hawbaker et al. 1961; Hojberg et al. 2005; Hu et al. 2004; Mei et al. 2010; Namkung et al. 2006; Wang et al. 2012; Xia et al. 2005). No effect on the anaerobic population was observed when the dietary copper level was < $200 \mathrm{mg} \mathrm{kg}^{-1}$ (Bunch et al. 1961; Hojberg et al. 2005; Mei et al. 2010; Varel et al. 1987). Interestingly, $250 \mathrm{mg} \mathrm{kg}^{-1}$ dietary $\mathrm{Cu}$ in the form of $\mathrm{CuSO}_{4}$ may reduce the total population of anaerobic bacteria in the colon, while $\mathrm{CuO}$ does not seem to have any effect even at $375 \mathrm{mg} \mathrm{kg}^{-1} \mathrm{Cu}$ (Hawbaker et al. 1961; Hojberg et al. 2005).

There is a growing interest in gut microbiota and human health, and pigs are considered to be ideal models for human nutrition research (Guilloteau et al. 2010). Our previous studies suggested a potential link between dietary copper levels and rat health; unabsorbed copper accumulated in the gut, altering the composition of its microbiome and subsequently inducing an inflammatory response. Tumor necrosis factor (TNF)- $\alpha$ may be the chief molecule that responds to microbiotic shifts under excessive copper exposure (Zhang et al. 2017a). Taken together, these findings confirm that high levels of dietary copper change the composition of the microflora, which may further alter its metabolic activities and affect porcine health. However, to date, information regarding the effects of microbiome-metabolome responses to dietary copper levels in the hindgut of piglets is limited.

In the current study, $16 \mathrm{~S}$ rRNA pyrosequencing and nontargeted metabolomic methods were designed and used to investigate the effect of dietary copper levels on microbiome-metabolome responses in piglets. This study evaluated the use of high levels of copper in the diet and explored the effect of copper level on the health of Suhuai suckling piglets to assess the safety and necessity of high levels of copper in feed.

\section{Materials and methods}

\section{Ethical approval}

This study was approved and implemented under the supervision of the Animal Protection and Utilization Committee of Nanjing Agricultural University (Nanjing, Jiangsu province, China). According to the Nanjing Agricultural University Animal Care and Use Guide, all pigs were raised on local commercial farms.

\section{Animals, housing, diets, and sampling}

Suhuai suckling piglets were used as the experimental model in this study. This breed was developed via hybridization of a local Huai sow with a Yorkshire pig in 1958, followed by decades of breeding. Suhuai pigs were approved as a new breed by the China National Commission of Animal Genetic Resources in 2011.

One hundred seventy-two piglets from 18 multiparous Suhuai sows (inseminated twice) were sorted into blocks by their anticipated farrowing dates and assigned to two rooms (nine litters/room, 10 piglets per litter). All piglets were individually weighed at $72 \mathrm{~h}$ postnatally. Within each litter, all piglets were chosen based on similar body weight (BW); BW and sex were balanced among the litters. Three treatments were randomly assigned to the litters within each room (six litters/treatment), which were also arranged in a factorial array. The treatments (factors) included copper supplementation from $\mathrm{Cu}$ sulfate $\left(\mathrm{CuSO}_{4}\right)$ : (i) a low-copper ( $\mathrm{LC}, 6 \mathrm{mg} \mathrm{kg}^{-1}$ ) diet containing no supplemental $\mathrm{Cu}$; (ii) a control $(\mathrm{CON}$, $20 \mathrm{mg} \mathrm{kg}^{-1}$ ) diet; or (iii) a high-copper (HC, $300 \mathrm{mg} \mathrm{kg}^{-1}$ ) diet. The prefeeding began in suckling piglets at 7 to 14 days of age, and the piglets were trained to feed every day. With the increase in feed intake, the amount of nursing was reduced. The corn/soybean-based diets were supplied throughout the experiment, which included the prefeeding period, conformed to the nutrient requirements of the National Research Council (Southern et al. 2012b) (Table 1). The piglets were allowed free access to feed and water during the 26-day (14-40 days of age) animal trial. Prior to weaning, three litters were chosen 
Table 1 Composition of the experimental diets $($ mean $\pm \mathrm{SD})$

\begin{tabular}{|c|c|c|c|}
\hline \multirow[t]{2}{*}{ Items } & \multicolumn{3}{|c|}{$\mathrm{Cu}$ supplementation, $\mathrm{mg} \mathrm{kg}^{-1}$ diet } \\
\hline & $\mathrm{LC}(6)$ & $\mathrm{CON}(20)$ & $\mathrm{HC}(300)$ \\
\hline \multicolumn{4}{|l|}{ Ingredient $(\%)$} \\
\hline Corn & & 69.00 & \\
\hline Soybean meal & & 14.00 & \\
\hline Extruded soybeans & & 5.00 & \\
\hline Self-made premix ${ }^{\mathrm{a}}$ & & 12.00 & \\
\hline \multicolumn{4}{|l|}{ Nutrition level $(\%)^{\mathrm{b}}$} \\
\hline Dry matter & & 87.24 & \\
\hline Crude protein & & 17.86 & \\
\hline Crude fat & & 1.98 & \\
\hline Crude fiber & & 4.15 & \\
\hline Ash & & 4.76 & \\
\hline Measured $\mathrm{Cu}$ value $\left(\mu \mathrm{g} \mathrm{g}^{-1}\right)$ & $5.90 \pm 1.04$ & $23.14 \pm 3.59$ & $295.31 \pm 14.80$ \\
\hline
\end{tabular}

${ }^{\text {a }}$ Ingredients: fish meal, choline chloride, vitamin, mineral elements, L-lysine hydrochloride, calcium hydro phosphate, stone powder, sodium chloride, enzyme preparation, flavoring agent, and sweetening agent. No antibiotics were added

${ }^{\mathrm{b}}$ Measured values

within each treatment, and blood and feces samples were collected from four piglets within each litter (two male and two female). Blood samples were obtained using glass tubes containing no anticoagulant, allowed to clot at room temperature and stored at $4{ }^{\circ} \mathrm{C}$ before harvest of serum by centrifugation (15 min at $3500 \mathrm{rpm})$. The serum and fecal samples were stored at $-80^{\circ} \mathrm{C}$ for subsequent analyses.

\section{Copper measurement}

The copper content in the fecal samples from suckling piglets were measured by inductively coupled plasma optical emission spectrometry (ICP-OES) (PerkinElmer, Waltham, USA). The feces $(500 \mu \mathrm{g})$ were dried and placed in a tube with $10 \mathrm{~mL}$ of a mixture of nitric acid (chemically pure) and perchloric acid (chemically pure) $(3: 1 v / v)$. After digestion overnight, tubes were heated from 100 to $240{ }^{\circ} \mathrm{C}$ for approximately $3 \mathrm{~h}$, and then the digests were brought to a constant volume with double-distilled deionized water (Zhang et al. 2017a).

\section{DNA extraction, 16S rRNA gene amplicon pyrosequencing, and sequence analysis}

The methods in this section are similar to those of our previous studies (Zhang et al. 2017a), in which the DNA was extracted from the piglet fecal samples with a QIAamp Fast DNA Stool Mini Kit (QIAGEN, Duesseldorf, Germany) and quantified with a NanoDrop spectrophotometer (NanoDrop 2000, NanoDrop Technologies, Waltham, USA).

The polymerase chain reaction (PCR) $\left(95{ }^{\circ} \mathrm{C}\right.$ for $5 \mathrm{~min}$, followed by 27 cycles of $95^{\circ} \mathrm{C}$ for $30 \mathrm{~s}, 55^{\circ} \mathrm{C}$ for $30 \mathrm{~s}$, and
$72{ }^{\circ} \mathrm{C}$ for $45 \mathrm{~s}$ and a final extension at $72{ }^{\circ} \mathrm{C}$ for $10 \mathrm{~min}$ ) was used to amplified the $\mathrm{V} 4-\mathrm{V} 5$ region of the $16 \mathrm{~S}$ rRNA gene; the primers were $341 \mathrm{~F}$ (5'-CCTAYGGGRBGCASCAG-3') and 806R (5'-GGACTACNNGGGTATCTAAT-3'). The AxyPrep DNA Gel Extraction Kit (Axygen Biosciences, Tewksbury, USA) and the QuantiFluor-ST kit (Promega, Madison, USA) were used to purify and quantify all PCR products. The purified amplicons were sequenced on an Illumina MiSeq platform by Biozeron Biotechnology (Shanghai, China). The raw reads were deposited into the National Center for Biotechnology Information (NCBI) Sequence Read Archive database (Accession Number SRP155696).

Raw fastq files were demultiplexed, quality-filtered using Quantitative Insights Into Microbial Ecology (QIIME, version 1.17, http://qiime.org/scripts/assign_taxonomy.html) with the following criteria: the 250-bp reads were truncated at any site receiving an average quality score $<20$ over a 10 -bp sliding window, discarding the truncated reads that were shorter than $50 \mathrm{bp}$; exact barcode matching, 2-nucleotide mismatch in primer matching, reads containing ambiguous characters were removed; only sequences that overlapped by more than $10 \mathrm{bp}$ were assembled according to their overlap sequence. Reads which could not be assembled were discarded. Operational taxonomic units (OTUs) were clustered with $97 \%$ similarity cutoff using UPARSE (version 7.1, http://drive5.com/uparse/) and chimeric sequences were identified and removed using UCHIME (Sun et al. 2016). The phylogenetic affiliation of each 16S rRNA gene sequence was analyzed by RDP Classifier (http://rdp.cme.msu.edu/) against the SILVA (SSU123, https://www.arb-silva.de) 16S rRNA database using a confidence threshold of 70\% (Amato et al. 2013). 


\section{Serum biochemical parameters analysis}

The serum inflammatory cytokines, oxidative and antioxidative enzymes, and indices of hepatic and renal function were measured with detection kits produced by Nanjing Jiancheng Bioengineering Institute (Nanjing, Jiangsu province, China); all examinations were performed according to the manufacturer's instructions.

\section{Sample preparation for gas chromatography-mass spectrometer analysis}

Fecal samples $(100 \mathrm{mg})$ were transferred into 5 -mL centrifuge tubes; $500 \mu \mathrm{L}$ of $\mathrm{ddH}_{2} \mathrm{O}\left(4^{\circ} \mathrm{C}\right)$ was added, and the tubes were vortexed for $60 \mathrm{~s}$. Next, $1 \mathrm{~mL}$ of methanol (precooled at $-20^{\circ} \mathrm{C}$ ) and $60 \mu \mathrm{L}$ of heptadecanoic acid $\left(0.2 \mathrm{mg} \mathrm{mL}^{-1}\right.$ stock in methanol), as an internal quantitative standard, were added and vortexed for $30 \mathrm{~s}$. The tubes were then placed into an ultrasound machine at $25{ }^{\circ} \mathrm{C}$ for $10 \mathrm{~min}$, incubated on ice for $30 \mathrm{~min}$, and centrifuged for $10 \mathrm{~min}$ at $12,000 \mathrm{rpm}\left(4^{\circ} \mathrm{C}\right)$, after which $1.2 \mathrm{~mL}$ of the supernatant was transferred into a new centrifuge tube. Samples were blow-dried by vacuum concentration, and then $60 \mu \mathrm{L}$ of $15 \mathrm{mg} \mathrm{mL}^{-1}$ methoxyamine pyridine solution was added. The sample was vortexed for $30 \mathrm{~s}$ and reacted for $120 \mathrm{~min}$ at $37^{\circ} \mathrm{C}$. Finally, $60 \mu \mathrm{L}$ of bis(trimethylsilyl)trifluoroacetamide reagent (containing $1 \%$ trimethyl chlorosilane) was added to the mixture, reacted for $90 \mathrm{~min}$ at $37^{\circ} \mathrm{C}$, and centrifuged at $12,000 \mathrm{rpm} 4{ }^{\circ} \mathrm{C}$ for $10 \mathrm{~min}$, and the supernatant was transferred into a bottle for inspection; $20 \mu \mathrm{L}$ of each sample extract was used for quality control (QC), and the remaining sample material was used for gas chromatography-mass spectrometer (GC-MS) test detection.

\section{GC-MS analysis of fecal metabolite profiles}

The derivatized sample $(1.0 \mu \mathrm{L})$ was injected in split mode into an Agilent 7890A (Agilent, CA, USA) system in a 20:1 split ratio using an autosampler. Gas chromatography was performed on an HP-5MS capillary column (Folsom, CA, USA) to separate the derivatives at a constant flow of $1 \mathrm{~mL} \min ^{-1}$ helium. The injection temperature was $280^{\circ} \mathrm{C}$, the interface was set to $150^{\circ} \mathrm{C}$, and the ion source was adjusted to $230{ }^{\circ} \mathrm{C}$. The temperature-rise programs were followed by an initial temperature of $60^{\circ} \mathrm{C}$ for $2 \mathrm{~min}, 10^{\circ} \mathrm{C} \mathrm{min}^{-1}$ up to
$300{ }^{\circ} \mathrm{C}$, and a steady $300{ }^{\circ} \mathrm{C}$ for $5 \mathrm{~min}$. Mass spectrometry (Agilent 5975C, Agilent, CA, USA) was determined in the full-scan method with a 35 to $750\left(\mathrm{mz}^{-1}\right)$ range.

\section{GC-MS data acquisition and processing}

Following raw data collection, compounds were identified by comparing the mass spectra and retention indices of all detected compounds with their reference standards and database in the National Institute of Standards and Technology (NIST, https://www.nist.gov/srd) database and NEW Wiley 9 mass spectra library database (Sun et al. 2016). The SIMCA-p software (version 13.0, Umetrics, Umea, Sweden) was used to conduct multivariate statistical analysis. The acquired GC-MS data were processed with partial least squares-discriminant analysis (PLS-DA) (Sun et al. 2016). The metabolites with variable important projection (VIP) values $>1.0$ and one-way analysis of variance (ANOVA) $P$ values $<0.05$ were considered as different metabolites among the three dietary groups. The MetaboAnalyst (v4.0, http://www. metaboanalyst.ca/faces/ModuleView.xhtml) online tool was used to process the metabolic pathways and metabolite set enrichment analysis (Xia et al. 2009).

\section{Statistical analysis}

The relative abundance of microbial communities in feces and data that did not follow a normal distribution were processed using the nonparametric Kruskal-Wallis test. The correlation analysis was performed by the Spearman or Pearson correlation tests. Significant differences were considered as $P<0.05$. The statistical analyses were conducted using SPSS Statistics (Version 22, https://www.ibm.com/analytics/spss-statisticssoftware) (Zhang et al. 2017a).

\section{Results}

\section{Dietary copper level affects the copper content in feces of suckling piglets}

As shown in Table 2, the fecal copper content in the HC group was significantly higher than that in the LC and
Table 2 Copper content in the feces of suckling piglets $($ mean $\pm \mathrm{SD})$

\begin{tabular}{llllll}
\hline Items & \multicolumn{2}{l}{ Cu supplementation, $\mathrm{mg} \mathrm{kg}^{-1}$ diet } & SEM & $\begin{array}{l}P \\
\text { value }\end{array}$ \\
\cline { 2 - 5 } & $\mathrm{LC}(6)$ & $\mathrm{CON}(20)$ & $\mathrm{HC}(300)$ & \\
\hline $\begin{array}{l}\text { Fecal copper content } \\
\left(\mu \mathrm{g} \mathrm{g}^{-1}\right)\end{array}$ & $195.01 \pm 34.55^{\mathrm{b}}$ & $275.62 \pm 54.65^{\mathrm{b}}$ & $1239.37 \pm 602.12^{\mathrm{a}}$ & 104.42 & $<0.05$ \\
\hline
\end{tabular}

Values within a row without a common superscript letter are significantly different $(P<0.05)$ 
CON groups $(P<0.05)$; there were no significant differences in fecal copper content between the LC and CON group $(P>0.05$; Table 2$)$.

\section{Effect of dietary copper level on the composition of fecal microbiota}

At a cutoff level of 3\%, no effect on the number of reads or OTUs was observed among the groups. The richness estimator Chaol tended to be decreased in the CON group $(P=$ $0.07)$; there were no significant differences in the richness estimator ACE or the Shannon and Simpson diversity indices among the groups $(P>0.05$; Table 3$)$.

At the phylum level, Bacteroidetes and Firmicutes were the predominant phyla in the fecal microbiota of piglets, with a total abundance $>90 \%$, followed by the phyla Spirochaetes, Proteobacteria, Fibrobacteres, and Euryarchaeota (Supplemental Fig. S1). The relative abundance of Firmicutes and Euryarchaeota was higher in the CON group than in the $\mathrm{HC}$ group, while the relative abundance of Fibrobacteres was higher in the HC group compared to the other groups $(P<0.05$; Fig. 1$)$.

At the genus level, the relative abundance levels of Ruminococcus, Dorea, and Corynebacterium were higher in the CON group and of Prevotellaceae UCG-004 in the HC group than in the other groups $(P<0.05)$. The relative abundance levels of Prevotellaceae UCG-001, Lachnospiraceae NK4A136 group, and Nesterenkonia were lower, while Coprococcus abundance was increased in the LC group compared to the CON group $(P<0.05)$; the abundance levels of Streptococcus and Fibrobacter were lower and the abundance levels of Halomonas and Methanobrevibacter were higher in the $\mathrm{HC}$ group than in the $\mathrm{CON}$ group; and the abundance levels of Acidaminococcus and Lachnospiraceae FCS020 group were lower in the HC group than in the LC group $(P<0.05$; Fig. 2a).

At the OTU level, the abundance levels of Oscillospira-, Rikenellaceae-, and Ruminococcus-related OTUs were lower, while Dorea-, Prevotella-, Ruminococcus-, and Anaerotruncus-related OTUs were higher in the CON group than in the LC group $(P<0.05)$; the abundance levels of Treponema- and Rikenellaceae-related OTUs were higher, while those of Methanobrevibacter-, Ruminococcus-, Dorea-, Prevotella-, and Oscillibacter-related OTUs were lower in the HC group than in the CON group $(P<0.05)$; and the abundance levels of Treponema- and Rikenellaceaerelated OTUs were higher in the $\mathrm{HC}$ group than in the LC group $(P<0.05$; Fig. $2 b)$.

\section{Dietary copper levels affect the biochemical parameters in the serum of suckling piglets}

Compared with the CON group, TNF- $\alpha(P<0.05)$ was decreased and the total antioxidant capacity (T-AOC) $(P<0.05)$ was increased in the HC group. Meanwhile, malondialdehyde (MDA) $(P=0.05)$, alanine aminotransferase (ALT) $(P<0.05)$, aspartate transaminase (AST) $(P<0.01)$, and total bile acid (TBA) $(P<0.05)$ were increased in the LC group; serum albumin $(P<0.05)$ was decreased in the HC group compared with the LC and CON groups; the serum blood urea nitrogen (BUN) $(P<0.01)$ was increased, and the superoxide dismutase (SOD) $(P=0.09)$ tended to be increased in the CON group compared with the LC and HC groups (Fig. 3).

\section{Correlations between fecal microbiota and serum biochemical parameters}

At the genus level, the abundance levels of Lachnospiraceae (NK4A136 and FCS020 groups) were positively correlated with MDA and albumin and negatively correlated with TAOC. The abundance of Ruminococcus was positively correlated with TNF- $\alpha$. The abundance levels of Halomonas and Methanobrevibacter were positively correlated with TNF- $\alpha$, albumin, and BUN. The abundance of Corynebacterium was positively correlated with TNF- $\alpha$ and albumin (Fig. 4a).

At the OTU level, the abundance levels of OTU413 (Erysipelotrichaceae), OTU789 (Methanobrevibacter), and OTU841 (Ruminococcus) were positively correlated with TNF- $\alpha$ and SOD $(P<0.05)$; the abundance level of
Table 3 Effect of dietary copper levels on the richness and diversity of fecal microbiota in suckling piglets $($ mean $\pm \mathrm{SD})$

\begin{tabular}{lcccrc}
\hline Items & \multicolumn{2}{l}{ Cu supplementation, $\mathrm{mg} \mathrm{kg}^{-1}$ diet } & SEM & $P$ value \\
\cline { 2 - 5 } & LC (6) & CON (20) & HC (300) & & \\
\hline Reads & $37,303.73 \pm 3732.58$ & $36,596.09 \pm 4675.63$ & $35,454.42 \pm 4924.50$ & 758.09 & 0.61 \\
OTUs & $628.00 \pm 75.80$ & $580.27 \pm 33.92$ & $627.08 \pm 60.39$ & 10.58 & 0.11 \\
ACE & $728.43 \pm 84.56$ & $681.21 \pm 44.48$ & $734.80 \pm 58.55$ & 11.49 & 0.12 \\
Chao1 & $742.31 \pm 79.03$ & $684.11 \pm 55.32$ & $744.85 \pm 63.08$ & 12.06 & 0.07 \\
Shannon & $4.70 \pm 0.25$ & $4.59 \pm 0.12$ & $4.64 \pm 0.28$ & 0.04 & 0.51 \\
Simpson & $0.022 \pm 0.008$ & $0.023 \pm 0.005$ & $0.025 \pm 0.010$ & 0.001 & 0.71 \\
\hline
\end{tabular}


Fig. 1 Effect of dietary copper level on the relative abundance of phyla in suckling piglets (relative abundance $>1 \%$ )

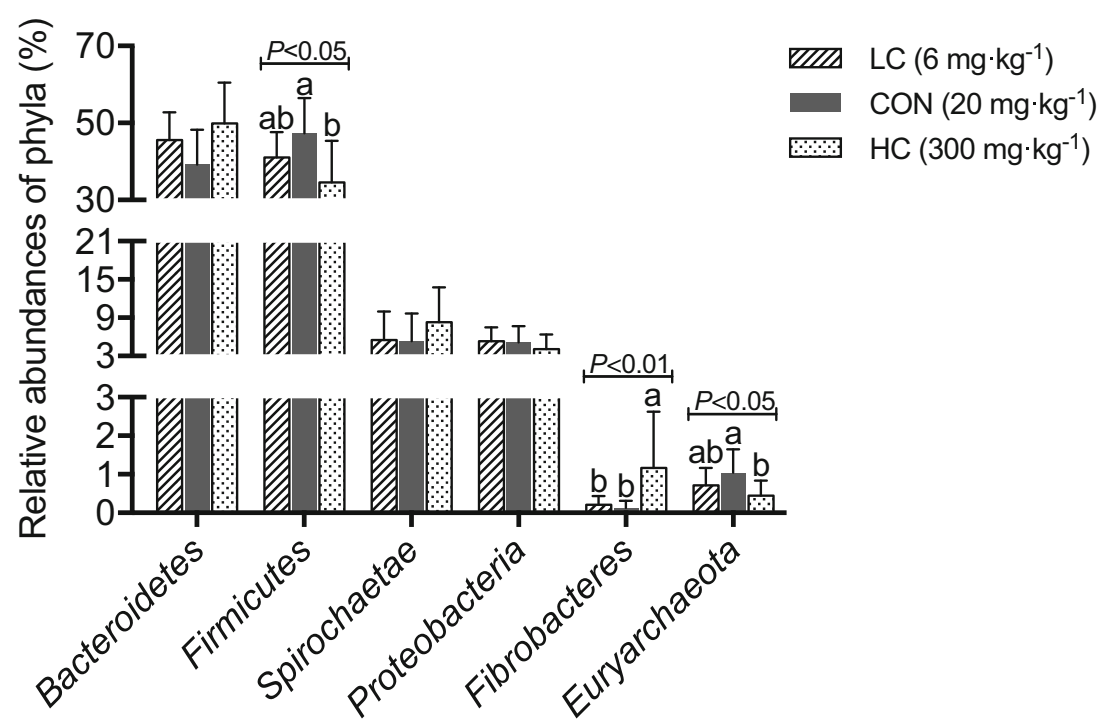

OTU756 (Prevotellaceae NK3B31 group) was negatively correlated with MDA $(P<0.05)$; the abundance levels of OTU104 (Rikenellaceae RC9 gut group), OTU1207 (Treponema), and OTU313 (Treponema) were positively correlated with ALT $(P<0.05)$; the abundance levels of OTU1102 (Ruminococcaceae UCG-005) and OTU841 (Ruminococcus) were negatively correlated with AST $(P<0.05)$; the abundance levels of Rikenellaceae RC9

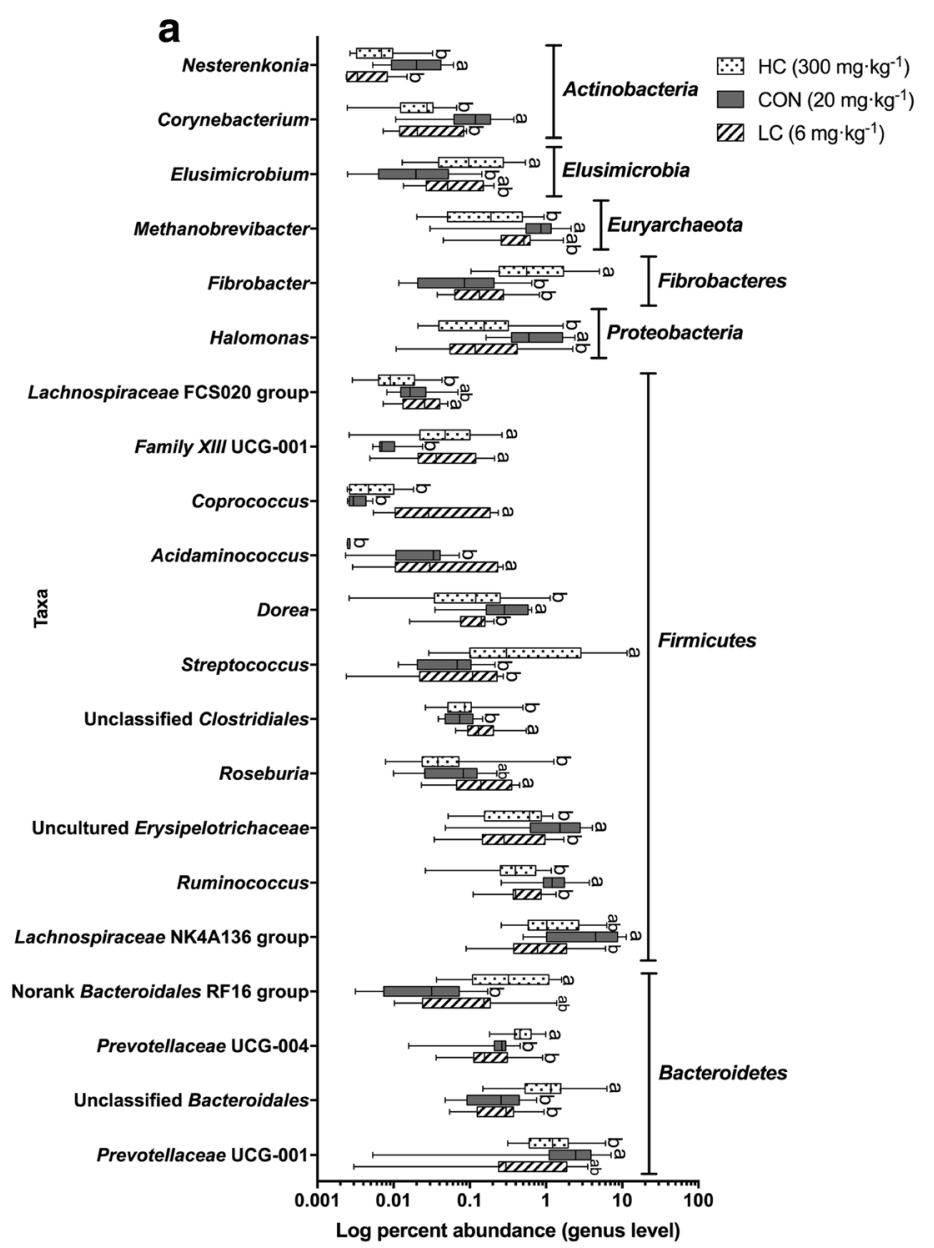

b

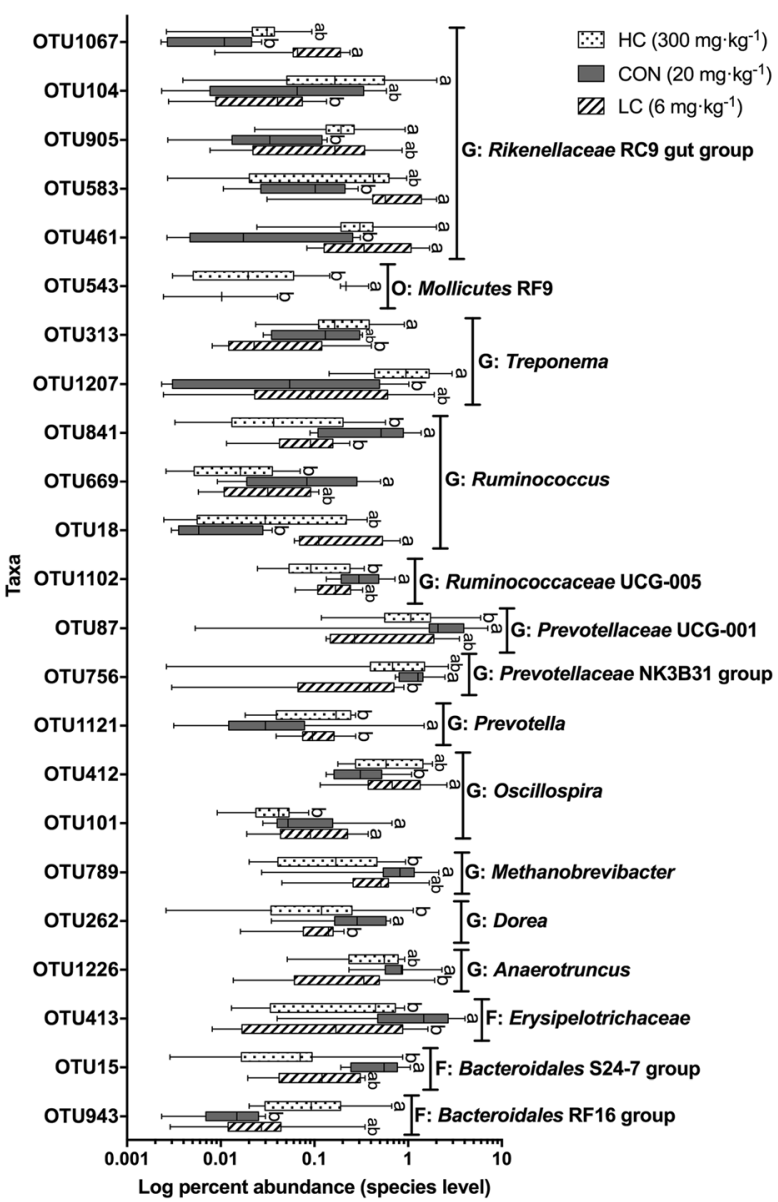

Fig. 2 Effect of dietary copper level on the relative abundances of fecal microbiota genera and OTUs in suckling piglets. a Genus level. b OTU level 
a

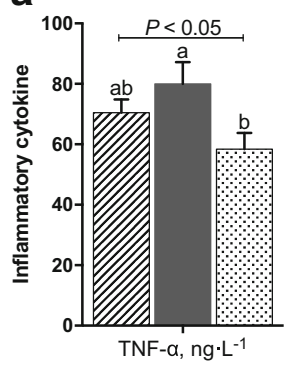

b

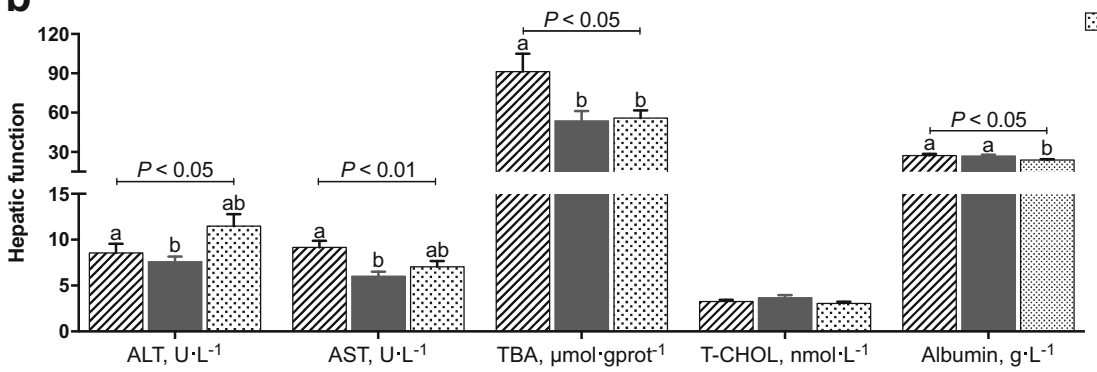

ZIA LC $\left(6 \mathrm{mg} \cdot \mathrm{kg}^{-1}\right)$

$\operatorname{CON}\left(20 \mathrm{mg} \cdot \mathrm{kg}^{-1}\right)$

HC $\left(300 \mathrm{mg} \cdot \mathrm{kg}^{-1}\right)$

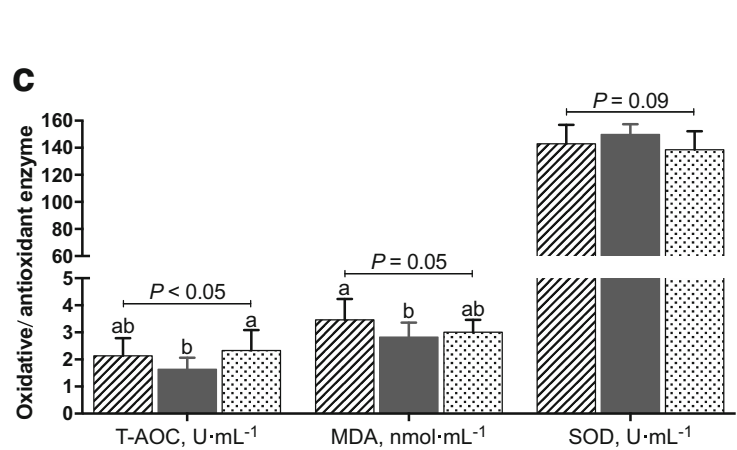

Fig. 3 Effect of dietary copper on serum biochemical parameters in suckling piglets. a Inflammatory cytokine. b Hepatic function. c Oxidative/antioxidative enzyme. d Renal function. TNF- $\alpha$, tumor necrosis factor- $\alpha$; ALT, alanine aminotransferase; AST, aspartate

gut group (OTU461, OTU583, and OTU1067) were positively correlated with TBA $(P<0.05)$; and the abundance levels of OTU15 (Bacteroidales S24-7 group) and OTU262 (Dorea) were positively correlated with BUN $(P<0.05)$ (Fig. 4b).

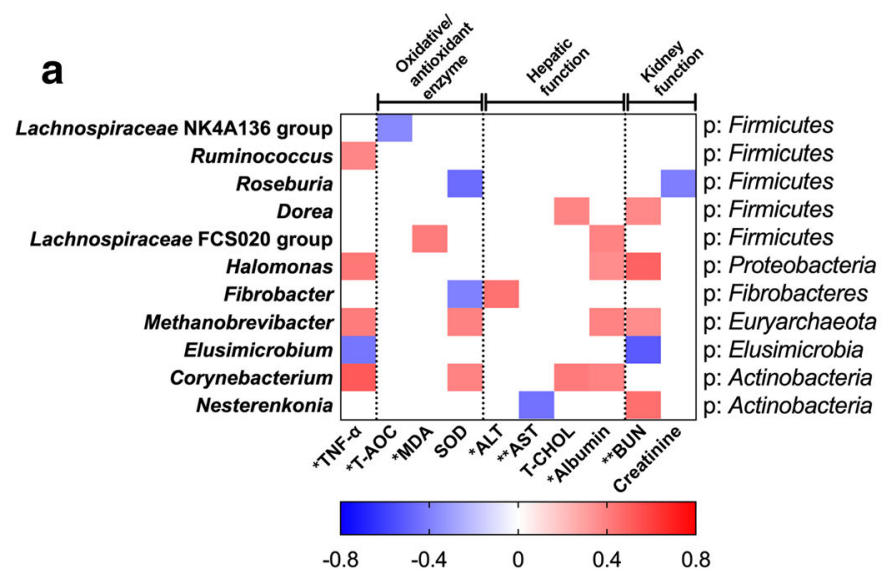

Fig. 4 Correlation analysis of microbiota (genus and OTU levels) and inflammatory cytokine, oxidation reduction, and hepatorenal function. a Genus level. b OTU level. The color is according to the Pearson coefficient distribution: red represents a positive correlation $(P<0.05)$,

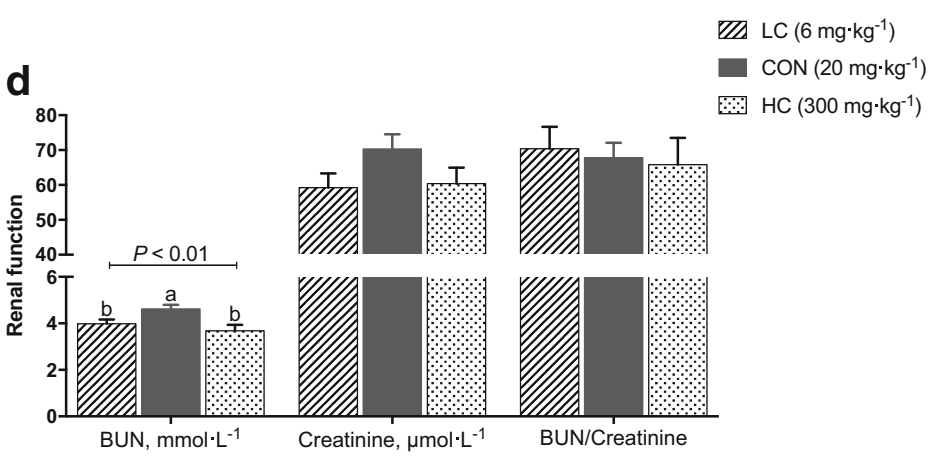

transaminase; TBA, total bile acid; T-CHOL, total cholesterol; T-AOC, total antioxidant capacity; MDA, malondialdehyde; SOD, superoxide dismutase; BUN, blood urea nitrogen

\section{Effect of dietary copper level on fecal metabolite profiles}

Overall, a total of 205 nontargeted peaks were detected, and 91 compounds were annotated based on a comparison with

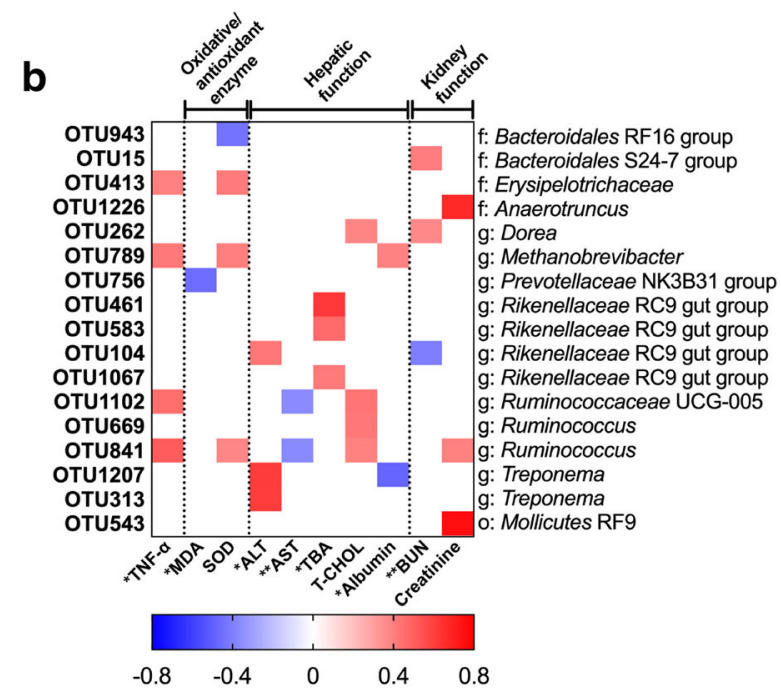

blue represents a negative correlation $(P<0.05)$, and white shows that the correlation was not significant $(P>0.05)$. *Significantly affected by dietary copper level $(P<0.05)$; **Significantly affected by dietary copper level $(P<0.01)$; p, phylum; o, order; f, family; g, genus 
reference compounds in available libraries or authentic reference standards. These metabolites included amino acids, carbohydrates, fatty acids, amines, polyols, organic acids, and nucleotides involved in multiple biochemical processes in suckling piglets. The key compounds responsible for differentiation were identified using the multivariate analysis method of PLS-DA (Supplemental Fig. S2).

Criteria including VIP $>1, P<0.05$, and one-way ANOVA $P<0.05$ were used to identify the compounds responsible for the difference between two and three dietary groups. A total of 47 significant fecal metabolites were identified for the three dietary groups (Supplemental Table S1). Compared with the CON group, 35 compounds were enriched in the LC group (Fig. 5a) and seven compounds were reduced and one compound was enriched in the HC group (Fig. 5b). Compared with the LC group, 42 compounds were reduced in the $\mathrm{HC}$ group (Fig. 5c). Further metabolic pathway enrichment analysis showed that dietary copper level had significant effects on protein biosynthesis, the urea cycle, galactose metabolism, gluconeogenesis, and amino acid metabolism (including the metabolism of arginine, proline, $\beta$-alanine, phenylalanine, tyrosine, and methionine; Fig. 6).

\section{Correlations between fecal microbiota and significant metabolites}

Fecal metabolites, fecal microbial genera, and OTUs with significant differences among the three groups were subjected to Pearson's correlation analysis. At the genus level, the relative abundance of Prevotellaceae UCG-004 was positively correlated with carbohydrates (glucose and mannose), organic acids (4-hydroxybenzoic acid), or polyols (myo-inositol) $(P<0.05)$; the relative abundance of Streptococcus was negatively correlated with amino acids (isoleucine, leucine, methionine, phenylalanine, serine, threonine, and tyrosine), nucleotides (inosine and pseudouridine), and organic acids (fumaric acid) $(P<0.05)$; and the relative abundance of Acidaminococcus was positively correlated with amines (ethanolamine), amino acids (homoserine), 9,12-(z,z)octadecadienoic acid, nucleotides (pseudouridine), and organic acids (malic acid) $(P<0.05$; Fig. 7a)

At the OTU level, the relative abundance of OTU583 was positively correlated with amines (ethanolamine and putrescine), amino acids (4-hydroxyproline, arginine, homoserine, and lysine), carbohydrates (arabinose, glucose, and mannose), organic acids (2-hydroxyglutaric acid, 2-methyl-butanedioic acid, and benzoic acid), and polyols (glycerol and myoinositol) $(P<0.05)$; the relative abundance of OTU1067 was positively correlated with amines (ethanolamine), amino acids (4-hydroxyproline, arginine, homoserine, lysine, methionine, ornithine, serine, and tyrosine), organic acids (2-methylbutanedioic acid), and polyols (glycerol) $(P<0.05)$; and the relative abundance of OTU18 was positively correlated with amino acids (4-hydroxyproline and ornithine), carbohydrates (fructose-6-phosphate, glucose-6-phosphate, and mannose-6phosphate), and polyols (glycerol) $(P<0.05$; Fig. 7b).

The significant fecal metabolites correlated with microbial genera and OTUs were used for further metabolic pathway enrichment analysis. The relative abundance levels of Coprococcus (family Lachnospiraceae) and OTU18 (family Ruminococcaceae) were positively correlated with energy metabolism pathways (gluconeogenesis, glycolysis, and pentose phosphate pathway); the abundance of Streptococcus was negatively correlated with amino acid metabolism pathways (protein biosynthesis, glycine, serine, threonine, methionine, phenylalanine, and tyrosine metabolism); and the abundance levels of OTU583 and OTU1067 (family Rikenellaceae) were positively correlated with amino acid metabolism pathways (protein biosynthesis, $\beta$-alanine, glycine, serine, threonine, and methionine metabolism; Fig. 8).

\section{Discussion}

It has been estimated that between 500 and 1000 bacterial species populate in the gastrointestinal (GI) tract, accounting for a total of approximately $10^{14}$ bacteria (Sonnenburg et al. 2004). In this study, most of the dietary copper in the HC group was not absorbed and was instead accumulated in the feces of suckling piglets, which is consistent with our previous studies in rats (Zhang et al. 2017a). Whether high levels of copper in the environment in which bacteria survive affect microbial communities in piglets requires further discussion.

The richness (ACE and Chao indices) and diversity (Shannon and Simpson indices) are important features of microbial communities (Chao et al. 1993; Shen et al. 2003). In our study, the richness and diversity indices were not affected by dietary copper level, in contrast to a previous study reporting that high dietary copper levels (100 to $200 \mathrm{mg} \mathrm{kg}^{-1}$ ) from $\mathrm{CuSO}_{4}$ significantly affect microbial species (diversity) in ileac (Namkung et al. 2006), cecal (Hojberg et al. 2005; Mei et al. 2010), and colonic (Namkung et al. 2006) chyme of piglets. In addition, microbial diversity was decreased in a $250 \mathrm{mg} \mathrm{kg}^{-1} \mathrm{Cu}$ diet compared with a diet containing no copper supplementation (Namkung et al. 2006). A possible reason for this difference is that the method used to investigate the microbial flora is inconsistent. In the GI ecosystem, most bacterial species have yet to be cultured. Because of the high costs and low throughput, studies on the diversity of microflora in the GI tract have been limited, even by using PCR, cloning, and sequencing as cultureindependent methods. However, the recent application of 16S rRNA gene sequence analysis and the development of pyrosequencing technology have enabled a more comprehensive exploration of microbial communities in the GI tract and their diversity (Chakravorty et al. 2007; Huber et al. 2007; 


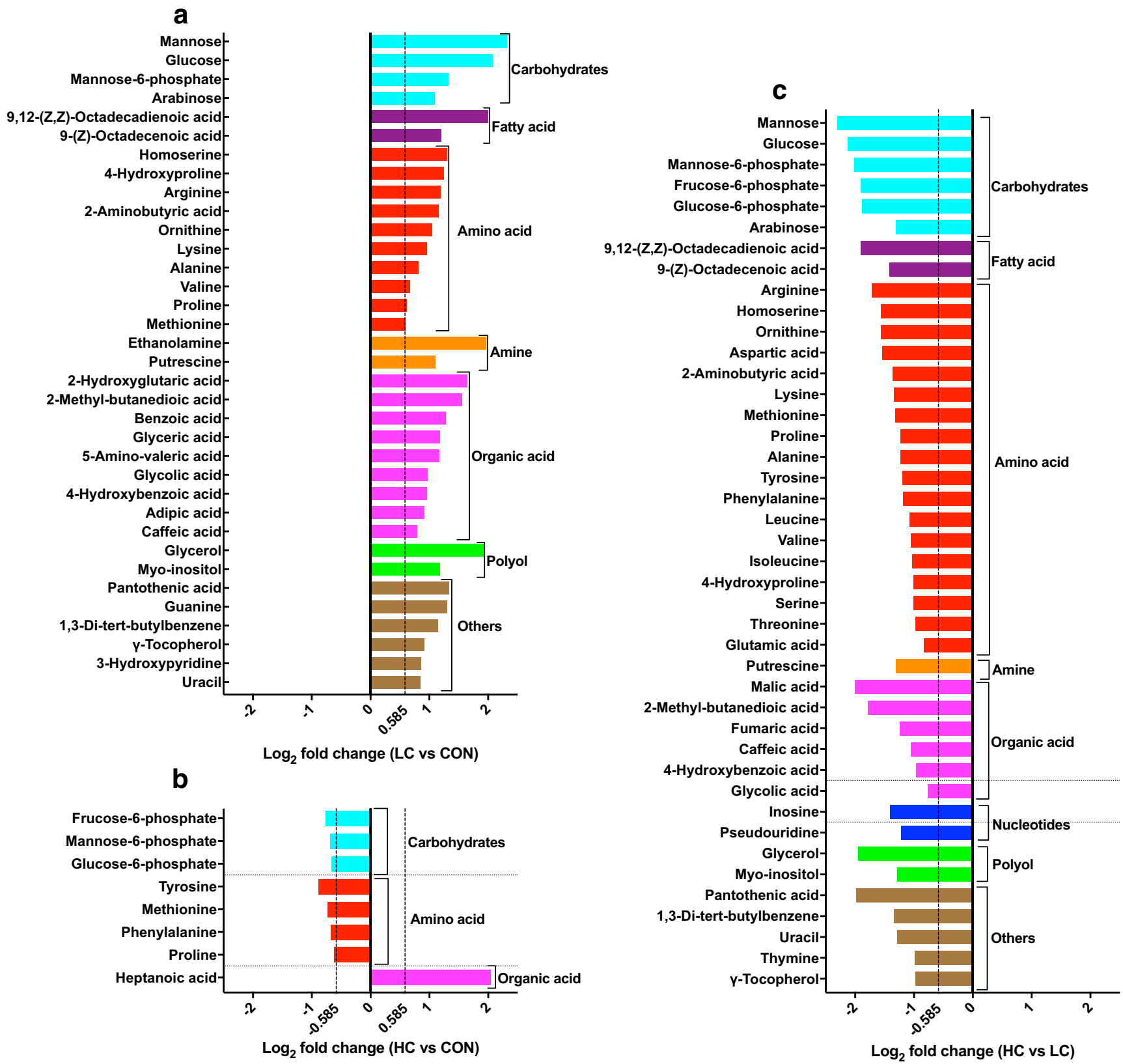

Fig. 5 Fold change of significant fecal metabolites. Significant metabolites accountable for class discrimination with VIP $>1$ and $P<0.05$ are listed. The fold change was calculated using the

Sogin et al. 2006); therefore, the approach of analyzing microbial communities based on 16S rRNA pyrosequencing is deemed more suitable (Dewar et al. 2013).

In our study, Firmicutes and Bacteroidetes were the most dominant phyla, similar to the findings of previous studies ( $\mathrm{Li}$ et al. 2017; Qin et al. 2010); low-level copper dietary supplementation (36-47 mg kg-1) from montmorillonite and highlevel $\left(200 \mathrm{mg} \mathrm{kg}^{-1}\right)$ copper supplementation from $\mathrm{CuSO}_{4}$ or $\mathrm{CuO}$ decreased the number of Clostridia in the cecum and colon of pigs (Hu et al. 2004; Song et al. 2013; Xia et al. 2005). Our $16 \mathrm{~S}$ rRNA gene pyrosequencing analysis normalized relative abundance of metabolites between each group: a LC vs. CON; b HC vs. CON; and c HC vs. LC. The threshold was 0.585 ; enrichment $>0.585$, reduction $\leq-0.585$

demonstrated that dietary copper levels affected the relative abundance of several Clostridia genera, including Coprococcus, Dorea, Roseburia, and Ruminococcus. However, changes in these genera were inconsistent; the abundance levels of butyrate-producing bacteria, such as Coprococcus, Roseburia (Duck et al. 2007; Klaring et al. 2015), and Acidaminococcus (Braune et al. 1999; JumasBilak et al. 2007), were decreased in the HC group, suggesting that high levels of dietary copper $\left(300 \mathrm{mg} \mathrm{kg}^{-1}\right)$ might inhibit the growth of beneficial bacteria in the gut. The decreased abundance of butyrate-producing bacteria in the hindgut of 


\section{Metabolite sets enrichment overview}

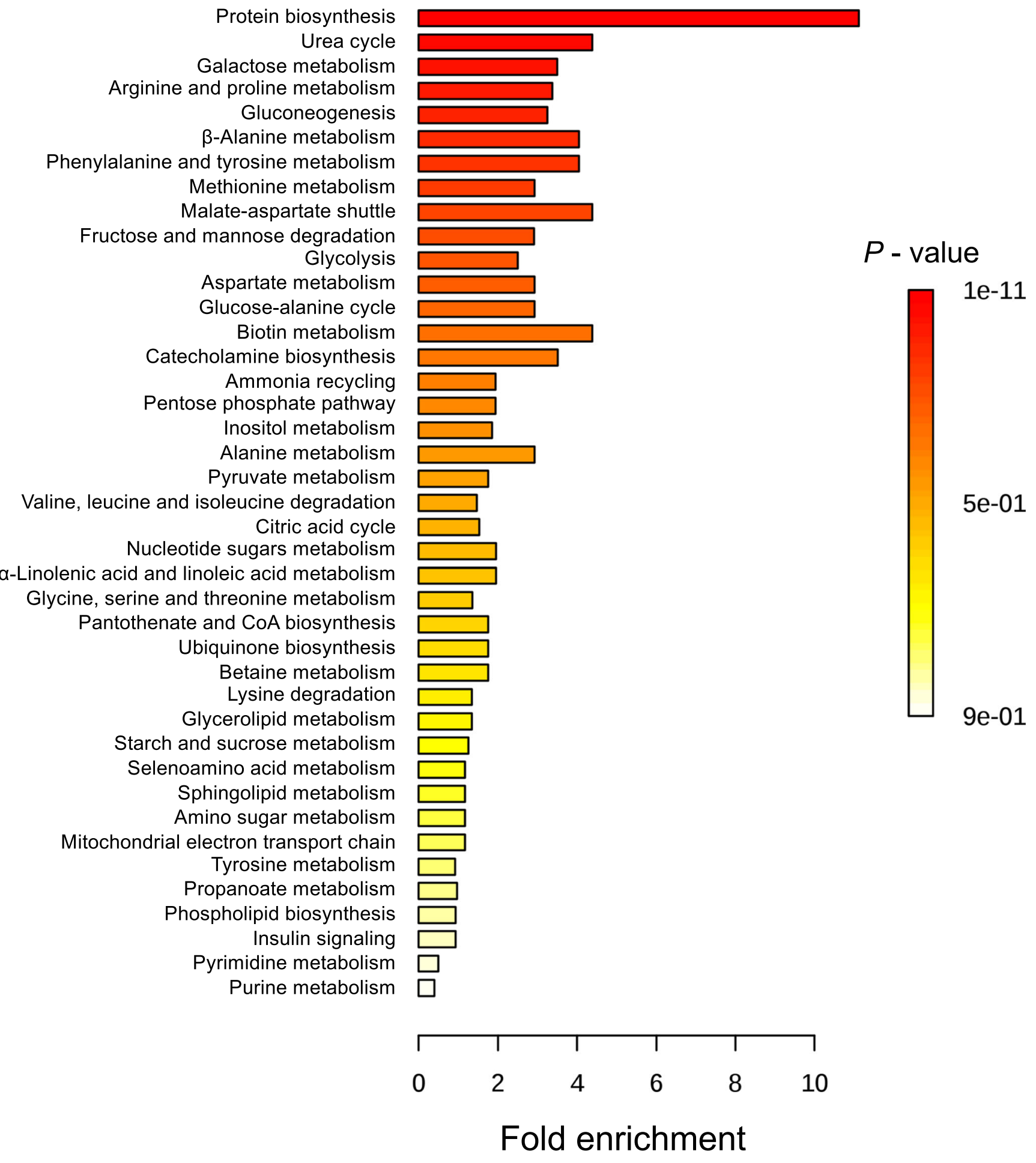

Fig. 6 Metabolic pathway enrichment analysis. Overview of metabolites that were enriched in suckling piglets fed different levels of dietary copper

piglets led to an increased $\mathrm{pH}$, while short-chain fatty acids (SCFA) reduced and weakened nutrient (such as dietary fiber) competition with other bacteria, as indicated by the increased abundance levels of the genera Streptococcus and Fibrobacter in the HC group. Most genus Streptococcus species are ureadecomposing bacteria, which could degrade the dietary 


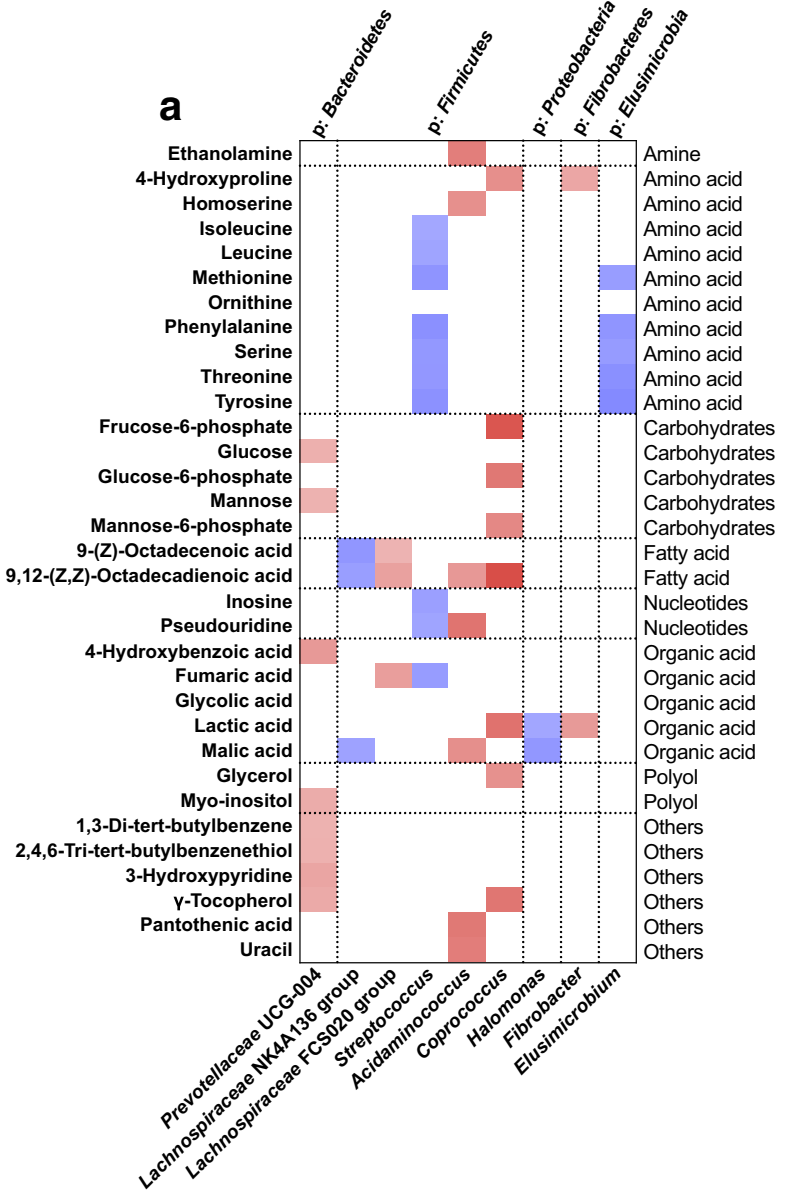

Fig. 7 Correlations between fecal microbiota and significant metabolites. Statistically significant correlations are presented, colored according to the Pearson coefficient distribution: red represents a positive correlation

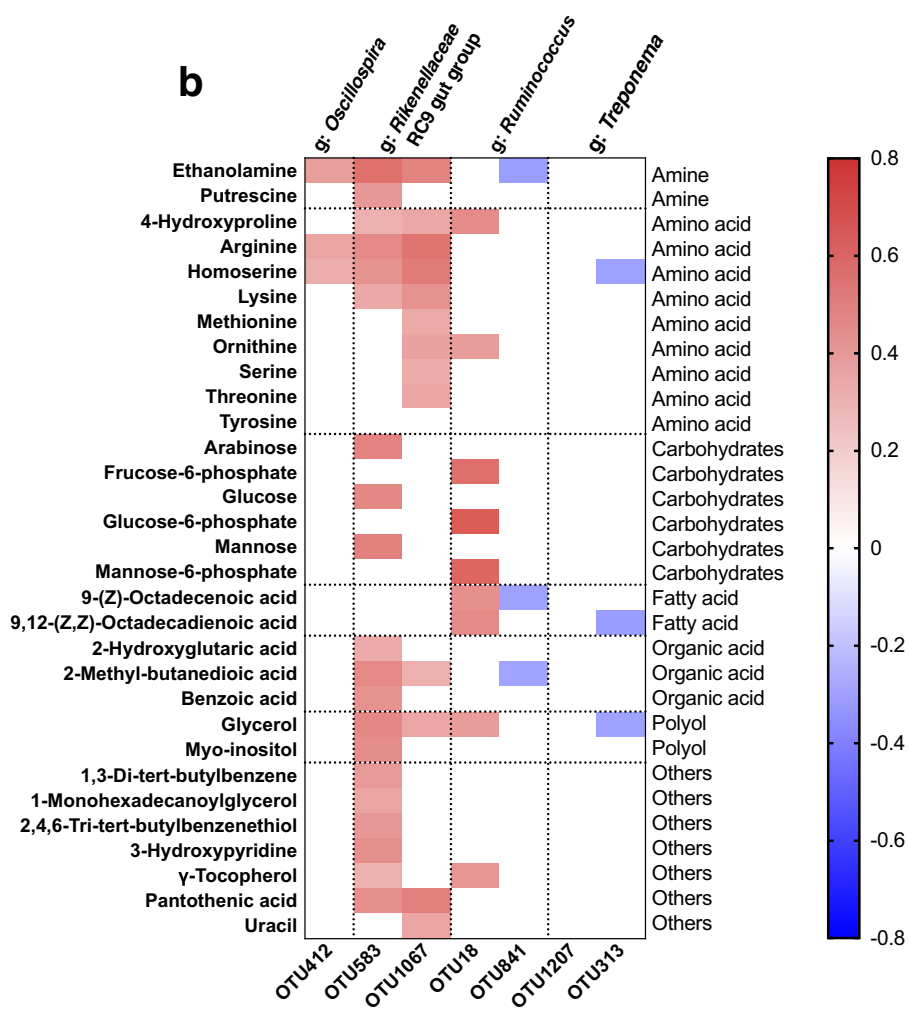

$(P<0.05)$, blue represents a negative correlation $(P<0.05)$, and white indicates that the correlation was not significant $(P>0.05)$; p, phylum; g, genus

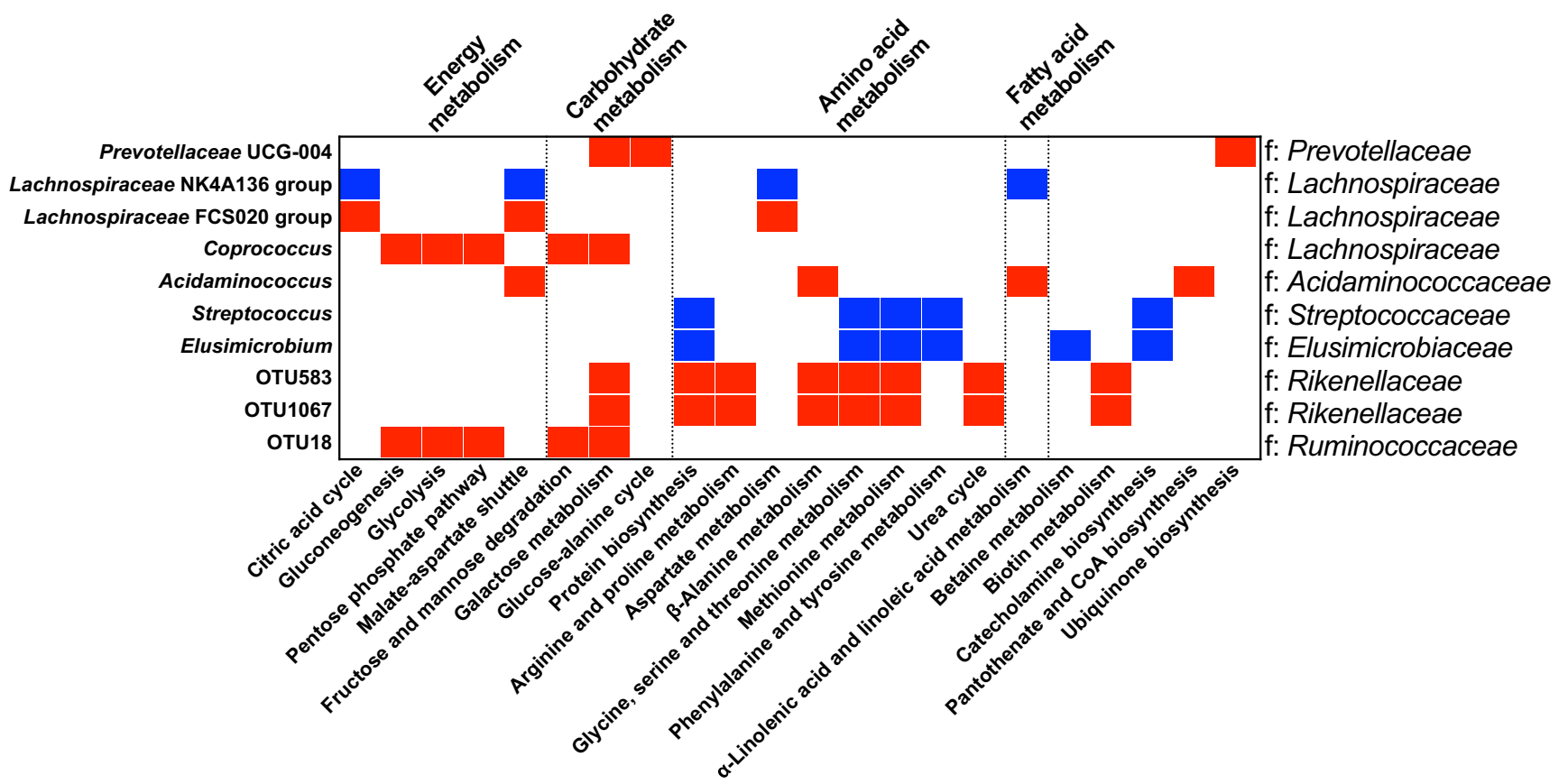

Fig. 8 Correlations between microbiota and enriched fecal metabolite pathways. Red represents a positive correlation $(P<0.05)$, blue represents a negative correlation $(P<0.05)$, and white indicates that the correlation was not significant $(P>0.05)$; $\mathrm{f}$, family 
nitrogen compounds into ammonia via the produced urease (Varel et al. 1987). The increased abundance of Streptococcus in the $\mathrm{HC}$ group might accelerate this degradation and elevate ammonia levels, causing toxic effects in the hindgut of piglets.

As we know, dietary different copper levels may affect the physiological parameters in the body, such as blood. To investigate the relationship between physiological parameters and fecal microbial communities in suckling piglets, the serum biochemical parameters were further analyzed. A decrease in serum TNF- $\alpha$ concentration in the HC group was observed in our study, suggesting that without antibiotic use, high levels of copper may have a potential role in decreasing the inflammatory response. Considering that SOD is a group of metalloenzymes that protect cells from superoxide radicals by degrading superoxide radicals into hydrogen peroxide (Hao et al. 2015), in the present study, the serum SOD level increased and MDA was decreased in the CON group compared with the $\mathrm{LC}$ and $\mathrm{HC}$ groups remarkably, suggesting that $20 \mathrm{mg} \mathrm{kg}^{-1} \mathrm{Cu}$ in the diet could effectively improve the antioxidant ability and protect tissues from oxidative damage. Because pigs fed a $6 \mathrm{mg} \mathrm{kg}^{-1} \mathrm{Cu}$ diet suffered increased oxidative stress, which induced possible damage in the liver, a hepatocellular injury usually results in the elevation of serum ALT and AST levels (Chang et al. 2011; Masubuchi et al. 2016), similarly, our results observed that serum ALT and AST were increased in the LC and HC groups compared with the CON group in suckling piglets. In our study, serum bile acids in the LC group were increased compared with the CON group. The measurement of changes in serum bile acids was considered a valuable biomarker, which is widely used for the diagnosis of hepatic disease (Fanali et al. 2012; Iwamura 1982; Masubuchi et al. 2016). Taking these results together, a dietary dose of $6 \mathrm{mg} \mathrm{kg}^{-1} \mathrm{Cu}$ did not maintain normal liver function, and $300 \mathrm{mg} \mathrm{kg}^{-1} \mathrm{Cu}$ might both have the potential risk of impaired liver function in suckling piglets. In the current study, dietary copper levels did not affect renal function due to the result of BUN/creatinine, elevation of which is considered a serum marker for identifying acute kidney injury (AKI) (Takaya et al. 2015); the body tissue was able to excrete any minerals above those needed by the body and did not store them in the kidney (Gowanlock et al. 2015).

Then, the correlation between fecal microbiota significantly affected by dietary copper level and serum biochemical parameters from suckling piglets were further analyzed in our study, helping us to understand the relationship between changes in gut microbiota and host health. In our study, the abundance of Lachnospiraceae was affected by dietary copper levels. These bacteria are the most active microbial components in the gut of healthy adults (Peris-Bondia et al. 2011), preventing the production of inflammatory cytokines and pathogen-induced intestinal dysfunction by fermenting carbohydrates into SCFA (Duncan et al. 2007; Reiff and Kelly 2010). The abundance of Lachnospiraceae was negatively correlated with T-AOC and positively correlated with MDA in serum, suggesting that these bacteria may cause changes in the redox balance of suckling piglets (Li et al. 2016). The abundance levels of Ruminococcus, Methanobrevibacter, and Corynebacterium were positively correlated with TNF- $\alpha$ in serum, which increased in the CON group, suggesting that altering these bacterial communities may influence the inflammatory response in piglets, consistent with our previous studies in rats (Zhang et al. 2017a). Meanwhile, correlation analysis shows that many bacteria were correlated with redox state and hepatic and renal function of piglets, and the abundance levels of these bacteria were affected by dietary copper level, which also suggested that the alteration of microbial communities may influence the serum biochemical parameters, further affecting the health of piglets.

Fecal metabolites reflect the final status of animal digestion, absorption, and metabolism of feed nutrients. The essential amino acids leucine, phenylalanine, and methionine and the conditionally essential amino acids proline and tyrosine were higher in the LC group than in the HC group (Supplemental Fig. S3), suggesting that the capacity or dietary protein digestion, absorption, and metabolism were lower in suckling piglets those fed with $6 \mathrm{mg} \mathrm{kg}^{-1} \mathrm{Cu}$ diet. A growing number of recent studies have shown that proline and leucine are involved in body protein synthesis (Beitz 2004; Columbus et al. 2015; Hernandez-Garcia et al. 2016; Manjarin et al. 2016; Soumeh et al. 2015; Zhang et al. 2017b) and animal growth (Festa and Thiele 2011; Kim et al. 2008; Mao et al. 2015) and that the metabolites 4-hydroxyproline, alanine, tyrosine, and methionine are involved with the tricarboxylic acid cycle (TCA) cycle (Beitz 2004), which provides the energy for organism life activities and is also connected with carbohydrate, fat, and protein metabolism. Taken together, these findings suggest that feed with $6 \mathrm{mg} \mathrm{kg}^{-1} \mathrm{Cu}$ supplementation has an adverse effect on the growth of piglets and may affect the health of piglets through the TCA cycle.

In pigs, dietary carbohydrates are mainly digested in the small intestine and absorbed as monosaccharides. Some carbohydrates are fermented in the form of SCFA following fermentation by intestinal microbes. Carbohydrates that have not been absorbed and degraded by the host are excreted in the feces (Southern et al. 2012a). In this study, arabinose, mannose, fructose-6-phosphate, mannose-6-phosphate, and glucose-6-phosphate levels were significantly higher in the LC than in the CON or HC group (Supplemental Fig. S3). These results suggest that dietary $6 \mathrm{mg} \mathrm{kg}^{-1}$ copper decreased monosaccharide absorption in piglets.

Diarrhea is a major health problem for piglets during growth. Previously, we found that the incidence of diarrhea was higher in piglets supplemented with $6 \mathrm{mg} \mathrm{kg}^{-1} \mathrm{Cu}$ than in the 20 and $300 \mathrm{mg} \mathrm{kg}^{-1}$ groups, which further confirmed the significantly upregulated levels of amines (putrescine) in the LC (6 mg kg ${ }^{-1}$ ) group (Supplemental Fig. S3). Amines are 
produced via the decarboxylation of amino acids by intestine microbiota and are rapidly absorbed in the colon. The enzyme diamine oxidase in the intestinal mucosa can catalyze the oxidation of histamines, putrescines, and other diamines to aldehydes for detoxification (Festa and Thiele 2011; Kim et al. 2008) via the liver or urine discharge (Htoo et al. 2007). Excessively high dietary protein levels or decreased digestion and absorption in the small intestine can increase the fermentation of amino acids by large intestine microbiota, leading to increased levels of putrescine and other amines and subsequently resulting in diarrhea in piglets (Gaskins 2001). In addition, copper is a cofactor of diamine oxidase; therefore, dietary copper levels may affect the level of amines (putrescine) in the gut and the incidence of diarrhea in piglets. Lactic acid and succinic acid are intermediate products of bacterial synthesis of propionic acid and butyric acid; the levels of these acids are low or undetectable in the gut when the microbiota structure remains stable. In the absence of lactic acid- and succinic acid-utilizing bacteria, intestinal epithelial cells slowly absorb and accumulate lactic acid and succinic acid, resulting in an increase in the osmotic pressure in the large intestine lumen, leading to increased intestinal mucosal water secretion and subsequently diarrhea. In this study, the levels of lactate and succinic acid were increased in fecal samples from LC $\left(6 \mathrm{mg} \mathrm{kg}^{-1}\right)$ piglets, which may be another reason for the higher diarrhea rate. In addition, the levels of organic acids were increased in the feces of piglets in the LC $\left(6 \mathrm{mg} \mathrm{kg}^{-1}\right)$ group (Supplemental Fig. S3), and this excessive level of organic acids decreased the $\mathrm{pH}$ in the hindgut; previous studies have reported that reduced $\mathrm{pH}$ in the intestine can prevent the colonization of pathogenic bacteria; however, low $\mathrm{pH}(\mathrm{pH}=5)$ can lead to impaired normal intestine function in rats and pigs and the inability to maintain water absorption in the gut lumen (Argenzio and Meuten 1991; Tsukahara and Ushida 2001).

Piglet feces metabolites can be divided into two groups: the body and the gut microbiota. The relative abundance of Prevotellaceae UCG-004 was increased in the HC (300 $\mathrm{mg} \mathrm{kg}^{-1}$ ) group, and Prevotella was the major fiberdegrading bacterium in the porcine intestine. Metabolomic analysis showed that the digestibility of carbohydrates in piglets from the $\mathrm{HC}\left(300 \mathrm{mg} \mathrm{kg}^{-1}\right)$ group increased, and the correlation and enrichment analysis demonstrated that the abundance of Prevotellaceae UCG-004 was significantly positively correlated with galactose metabolism and the glucosealanine cycle (Fig. 8), suggesting that dietary copper levels may affect the digestion and utilization of carbohydrates by influencing the relative abundance of bacteria associated with carbohydrate metabolism in the suckling piglet intestine. The family Lachnospiraceae genera Coprococcus and Acidaminococcus produce butyrate via the pyruvate pathway; their relative abundance levels were significantly positively correlated with carbohydrate metabolic pathways (citrate cycle, malate shuttle, gluconeogenesis, pentose phosphate pathway, and glycolysis; Fig. 8). The abundance of OTU18 (Ruminococcus) was positively correlated with carbohydrate metabolism pathways (glycolysis, gluconeogenesis, pentose phosphate pathway, fructose, mannose, and galactose metabolism), and the abundance levels of OTU583 and OTU1067 (Rikenellaceae RC9 gut group) were positively correlated with small molecule containing $\mathrm{N}$ metabolism pathways (protein biosynthesis, urea cycle, methionine, glycine, serine, threonine, arginine, and valine metabolism; Fig. 8). The abundance levels of these bacteria were increased in the LC $\left(6 \mathrm{mg} \mathrm{kg}^{-1}\right.$ ) group, suggesting that dietary copper level may affect the metabolism of carbohydrates and small $\mathrm{N}$ containing molecules in piglets by altering the abundance of these bacteria to some extent. Interestingly, dietary copper $\left(6 \mathrm{mg} \mathrm{kg}^{-1}\right)$ had a certain effect on the metabolic homeostasis of piglets.

Intestinal microbes are involved in protein metabolism, and three transcription factors involved in the regulation of methionine metabolism were identified in Streptococcus (Kovaleva and Gelfand 2007), suggesting that Streptococcus can participate in methionine metabolism; this partially explains the negative correlation between Streptococcus and the methionine metabolism pathway (Fig. 8). The relative abundance of Streptococcus was increased and methionine was decreased in fecal samples from the $\mathrm{HC}\left(300 \mathrm{mg} \mathrm{kg}^{-1}\right)$ group, possibly because Streptococcus degrades the nitrogen compounds (methionine) in feed into ammonia (Varel et al. 1987), which confirms the negative correlation between Streptococcus and methionine (Fig. 7). Therefore, the decreased nitrogen compounds in piglet feces from the $\mathrm{HC}\left(300 \mathrm{mg} \mathrm{kg}^{-1}\right)$ group and increased protein digestibility could also be due to an increase in the relative abundance of certain bacteria, accelerating the use of undigested nitrogenous compounds in the hindgut of piglets.

The present study investigated the microbiomemetabolome response in the hindgut of piglets fed different copper level diets. We found that consumption of diets with different copper levels differentially altered the microbial community composition and metabolic pathways in the hindgut, thus affecting the health of piglets receiving those diets. These alterations may help us assess the safety and necessity of excess $\mathrm{Cu}$ supplementation in feed and elucidate the impacts of copper intake on the health of animals and humans.

Acknowledgments This part of the work was assisted by Huaiyin breeding farm in China.

Author contributions W.Y., W.Z., and F.Z. conceived and designed the study; F.Z. and Y.X. performed the experiments; F.Z. organized the database and performed the statistical analysis; and W.Y. and F.Z. wrote the manuscript. 
Funding This research was supported by the earmarked fund for Jiangsu Agricultural Industry Technology System (JATS[2018]287), the National Natural Science Foundation of China (31372321), and the Fundamental Research Funds for Central Universities (KYD201809).

\section{Compliance with ethical standards}

Conflict of interest The authors declare that they have no conflict of interest.

Ethical approval All applicable international, national, and institutional guidelines for the care and use of animals were followed. This article does not contain any studies with human participants performed by any of the authors.

Open Access This article is distributed under the terms of the Creative Commons Attribution 4.0 International License (http:// creativecommons.org/licenses/by/4.0/), which permits unrestricted use, distribution, and reproduction in any medium, provided you give appropriate credit to the original author(s) and the source, provide a link to the Creative Commons license, and indicate if changes were made.

Publisher's Note Springer Nature remains neutral with regard to jurisdictional claims in published maps and institutional affiliations.

\section{References}

Amato KR, Yeoman CJ, Kent A, Righini N, Carbonero F, Estrada A, Gaskins HR, Stumpf RM, Yildirim S, Torralba M, Gillis M, Wilson BA, Nelson KE, White BA, Leigh SR (2013) Habitat degradation impacts black howler monkey (Alouatta pigra) gastrointestinal microbiomes. ISME J 7(7):1344-1353. https://doi.org/10. 1038/ismej.2013.16

Argenzio RA, Meuten DJ (1991) Short chain fatty acids induce reversible injury of porcine colon. Dig Dis Sci 36(10):1459-1468

Armstrong TA, Cook DR, Ward MM, Williams CM, Spears JW (2004) Effect of dietary copper source (cupric citrate and, cupric sulfate) and concentration on growth performance and fecal copper excretion in weanling pigs. J Anim Sci 82(4):1234-1240. https://doi.org/ $10.2527 / 2004.8241234 \mathrm{x}$

Baker-Austin C, Wright MS, Stepanauskas R, McArthur JV (2006) Coselection of antibiotic and metal resistance. Trends Microbiol 14(4): 176-182. https://doi.org/10.1016/j.tim.2006.02.006

Beitz DC (2004) Protein and amino acid metabolism. In: Reece WO (ed) Dukes' physiology of domestic animals. 12th edn. Cornell University Press, Ithaca and London, pp 535-552

Braune A, Bendrat K, Rospert S, Buckel W (1999) The sodium ion translocating glutaconyl-CoA decarboxylase from Acidaminococcus fermentans: cloning and function of the genes forming a second operon. Mol Microbiol 31(2):473-487. https:// doi.org/10.1046/j.1365-2958.1999.01189.x

Brown NL, Rouch DA, Lee BTO (1992) Copper resistance determinants in bacteria. Plasmid 27(1):41-51. https://doi.org/10.1016/0147619X(92)90005-U

Bunch RJ, Speer VC, Hays VW, Hawbaker JH, Catron DV (1961) Effects of copper sulfate, copper oxide and chlortetracycline on baby pig performance. J Anim Sci 20(4):723-726. https://doi.org/10.2134/ jas1961.204723x

Chakravorty S, Helb D, Burday M, Connell N, Alland D (2007) A detailed analysis of $16 \mathrm{~S}$ ribosomal RNA gene segments for the diagnosis of pathogenic bacteria. J Microbiol Methods 69(2):330 339. https://doi.org/10.1016/j.mimet.2007.02.005

Chang YY, Chou CH, Chiu CH, Yang KT, Lin YL, Weng WL, Chen YC (2011) Preventive effects of taurine on development of hepatic steatosis induced by a high-fat/cholesterol dietary habit. J Agric Food Chem 59(1):450-457. https://doi.org/10.1021/jf103167u

Chao A, Ma MC, Yang MCK (1993) Stopping rules and estimation for recapture debugging with unequal failure rates. Biometrika 80(1): 193-201. https://doi.org/10.2307/2336768

Columbus DA, Steinhoff-Wagner J, Suryawan A, Nguyen HV, Hernandez-Garcia A, Fiorotto ML, Davis TA (2015) Impact of prolonged leucine supplementation on protein synthesis and lean growth in neonatal pigs. Am J Physiol Endocrinol Metab 309(6): 601-610. https://doi.org/10.1152/ajpendo.00089.2015

Dewar ML, Arnould JP, Dann P, Trathan P, Groscolas R, Smith S (2013) Interspecific variations in the gastrointestinal microbiota in penguins. Microbiologyopen 2(1):195-204. https://doi.org/10.1002/mbo3.66

Duck LW, Walter MR, Novak J, Kelly D, Tomasi M, Cong YZ, Elson CO (2007) Isolation of flagellated bacteria implicated in Crohn's disease. Inflamm Bowel Dis 13(10):1191-1201. https://doi.org/10. 1002/ibd.20237

Duncan SH, Louis P, Flint HJ (2007) Cultivable bacterial diversity from the human colon. Lett Appl Microbiol 44(4):343-350. https://doi. org/10.1111/j.1472-765X.2007.02129.x

Fanali G, di Masi A, Trezza V, Marino M, Fasano M, Ascenzi P (2012) Human serum albumin: from bench to bedside. Mol Asp Med 33(3): 209-290. https://doi.org/10.1016/j.mam.2011.12.002

Festa RA, Thiele DJ (2011) Copper: an essential metal in biology. Curr Biol 21(21):877-883. https://doi.org/10.1016/j.cub.2011.09.040

Fry RS, Ashwell MS, Lloyd KE, O’Nan AT, Flowers WL, Stewart KR, Spears JW (2012) Amount and source of dietary copper affects small intestine morphology, duodenal lipid peroxidation, hepatic oxidative stress, and mRNA expression of hepatic copper regulatory proteins in weanling pigs. J Anim Sci 90(9):3112-3119. https://doi. org/10.2527/jas.2011-4403

Gaskins HR (2001) Intestinal bacteria and their influence on swine growth. In: Lewis AJ, Southern LL (eds) Swine nutrition. Intestinal bacteria and their influence on swine growth, 2nd edn. CRC Press, New York, pp 587-610

Goff JP (2004) Minerals. In: Reece WO (ed) Dukes' physiology of domestic animals. Minerals, 12th edn. Cornell University Press, Ithaca and London, pp 575-599

Gowanlock DW, Mahan DC, Jolliff JS, Hill GM (2015) Evaluating the influence of National Research Council levels of copper, iron, manganese, and zinc using organic (Bioplex) minerals on resulting tissue mineral concentrations, metallothionein, and liver antioxidant enzymes in grower-finisher swine diets. J Anim Sci 93(3):11491156. https://doi.org/10.2527/jas2014-8173

Guilloteau P, Zabielski R, Hammon HM, Metges CC (2010) Nutritional programming of gastrointestinal tract development. Is the pig a good model for man? Nutr Res Rev 23(1):4-22. https://doi.org/10.1017/ S0954422410000077

Hao RR, Li QH, Zhao JQ, Li HF, Wang WW, Gao JJ (2015) Effects of grape seed procyanidins on growth performance, immune function and antioxidant capacity in weaned piglets. Livest Sci 178(2015): 237-242. https://doi.org/10.1016/j.livsci.2015.06.004

Hasman H, Aarestrup FM (2002) tcrB, a gene conferring transferable copper resistance in Enterococcus faecium: occurrence, transferability, and linkage to macrolide and glycopeptide resistance. Antimicrob Agents Chemother 46(5):1410-1416. https://doi.org/ 10.1128/AAC.46.5.1410-1416.2002

Hawbaker JA, Speer VC, Hays VW, Catron DV (1961) Effect of copper sulfate and other chemotherapeutics in growing swine rations. J Anim Sci 20(1):163-167. https://doi.org/10.2134/jas1961.201163x

Hernandez-Garcia AD, Columbus DA, Manjarin R, Nguyen HV, Suryawan A, Orellana RA, Davis TA (2016) Leucine 
supplementation stimulates protein synthesis and reduces degradation signal activation in muscle of newborn pigs during acute endotoxemia. Am J Physiol Endocrinol Metab 311(4):791-801. https://doi.org/10.1152/ajpendo.00217.2016

Hojberg O, Canibe N, Poulsen HD, Hedemann MS, Jensen BB (2005) Influence of dietary zinc oxide and copper sulfate on the gastrointestinal ecosystem in newly weaned piglets. Appl Environ Microbiol 71(5):2267-2277. https://doi.org/10.1128/Aem.71.5.2267-2277.2005

Hölzel CS, Müller C, Harms KS, Mikolajewski S, Schäfer S, Schwaiger $\mathrm{K}$, Bauer J (2012) Heavy metals in liquid pig manure in light of bacterial antimicrobial resistance. Environ Res 113(2012):21-27. https://doi.org/10.1016/j.envres.2012.01.002

Htoo JK, Araiza BA, Sauer WC, Rademacher M, Zhang Y, Cervantes M, Zijlstra RT (2007) Effect of dietary protein content on ileal amino acid digestibility, growth performance, and formation of microbial metabolites in ileal and cecal digesta of early-weaned pigs. J Anim Sci 85(12):3303-3312. https://doi.org/10.2527/jas.2007-0105

$\mathrm{Hu} \mathrm{CH}$, Xia MS, Xu ZR, Xiong L (2004) Effects of copper bearing montmorillonite on growth performance and digestive function of growing pigs. Asian Australas J Anim Sci 17(11):1575-1581. https://doi.org/10.5713/ajas.2004.1575

Huang YL, Ashwell MS, Fry RS, Lloyd KE, Flowers WL, Spears JW (2015) Effect of dietary copper amount and source on copper metabolism and oxidative stress of weanling pigs in short-term feeding. J Anim Sci 93(6):2948-2955. https://doi.org/10.2527/jas2014-8082

Huber JA, Mark Welch D, Morrison HG, Huse SM, Neal PR, Butterfield DA, Sogin ML (2007) Microbial population structures in the deep marine biosphere. Science 318(5847):97-100. https://doi.org/10. 1126/science.1146689

Iwamura K (1982) Clinical aspects of bile acid metabolism in liver diseases. Tokai J Exp Clin Med 7(1):7-29

Jondreville C, Revy PS, Dourmad JY (2003) Dietary means to better control the environmental impact of copper and zinc by pigs from weaning to slaughter. Livest Prod Sci 84(2):147-156. https://doi. org/10.1016/j.livprodsci.2003.09.011

Jumas-Bilak E, Carlier JP, Jean-Pierre H, Mory F, Teyssier C, Gay B, Campos J, Marchandin H (2007) Acidaminococcus intestini sp nov., isolated from human clinical samples. Int J Syst Evol Microbiol 57: 2314-2319. https://doi.org/10.1099/ijs.0.64883-0

Kellogg TF, Hays VW, Catron DV, Quinn LY, Speer VC (1966) Effect of dietary chemotherapeutics on the performance and fecal flora of baby pigs. J Anim Sci 25(4):1102-1106. https://doi.org/10.2134/ jas1966.2541102x

Kim BE, Nevitt T, Thiele DJ (2008) Mechanisms for copper acquisition, distribution and regulation. Nat Chem Biol 4(3):176-185. https:// doi.org/10.1038/nchembio. 72

Klaring K, Just S, Lagkouvardos I, Hanske L, Haller D, Blaut M, Wenning M, Clavel T (2015) Murimonas intestini gen. nov., sp nov., an acetate-producing bacterium of the family Lachnospiraceae isolated from the mouse gut. Int J Syst Evol Microbiol 65:870-878. https://doi.org/10.1099/ijs.0.000030

Kovaleva GY, Gelfand MS (2007) Transcriptional regulation of the methionine and cysteine transport and metabolism in Streptococci. FEMS Microbiol Lett 276(2):207-215. https://doi.org/10.1111/j. 1574-6968.2007.00934.x

Li KK, Zhuo C, Teng CY, Yu SM, Wang X, Hu Y, Ren GM, Yu M, Qu JJ (2016) Effects of Ganoderma lucidum polysaccharides on chronic pancreatitis and intestinal microbiota in mice. Int J Biol Macromol 93:904-912. https://doi.org/10.1016/j.ijbiomac.2016.09.029

Li PH, Niu Q, Wei QT, Zhang YQ, Ma X, Kim SW, Lin MX, Huang RH (2017) Microbial shifts in the porcine distal gut in response to diets supplemented with Enterococcus faecalis as alternatives to antibiotics. Sci Rep 7:41395. https://doi.org/10.1038/srep41395

Lu L, Wang RL, Zhang ZJ, Steward FA, Luo XG, Liu B (2010) Effect of dietary supplementation with copper sulfate or tribasic copper chloride on the growth performance, liver copper concentrations of broilers fed in floor pens, and stabilities of vitamin $\mathrm{E}$ and phytase in feeds. Biol Trace Elem Res 138(1-3):181-189. https://doi.org/10. 1007/s12011-010-8623-3

Ma YL, Zanton GI, Zhao J, Wedekind K, Escobar J, Vazquez-Anon M (2015) Multitrial analysis of the effects of copper level and source on performance in nursery pigs. J Anim Sci 93(2):606-614. https://doi. org/10.2527/jas2014-7796

Manjarin R, Columbus DA, Suryawan A, Nguyen HV, Hernandez-Garcia AD, Hoang NM, Fiorotto ML, Davis T (2016) Leucine supplementation of a chronically restricted protein and energy diet enhances mTOR pathway activation but not muscle protein synthesis in neonatal pigs. Amino Acids 48(1):257-267. https://doi.org/10.1007/ s00726-015-2078-y

Mao XB, Liu MH, Tang J, Chen H, Chen DW, Yu B, He J, Yu J, Zheng P (2015) Dietary leucine supplementation improves the mucin production in the jejunal mucosa of the weaned pigs challenged by porcine rotavirus. PLoS One 10(9):e0137380. https://doi.org/10. 1371/journal.pone. 0137380

Masubuchi N, Nishiya T, Imaoka M, Mizumaki K, Okazaki O (2016) Promising toxicological biomarkers for the diagnosis of liver injury types: bile acid metabolic profiles and oxidative stress marker as screening tools in drug development. Chem Biol Interact 255(2016):74-82. https://doi.org/10.1016/j.cbi.2015.09.012

Mei SF, Yu B, Ju CF, Zhu D, Chen DW (2010) Effect of different levels of copper on growth performance and cecal ecosystem of newly weaned piglets. Ital J Anim Sci 9(4):378-381. https://doi.org/10. 4081/ijas.2010.e71

Namkung H, Gong J, Yu H, de Lange CFM (2006) Effect of pharmacological intakes of zinc and copper on growth performance, circulating cytokines and gut microbiota of newly weaned piglets challenged with coliform lipopolysaccharides. Can J Anim Sci 86(4): 511-522. https://doi.org/10.4141/A05-075

Peris-Bondia F, Latorre A, Artacho A, Moya A, D'Auria G (2011) The active human gut microbiota differs from the total microbiota. PLoS One 6(7):e22448. https://doi.org/10.1371/journal.pone.0022448

Puig S, Thiele DJ (2002) Molecular mechanisms of copper uptake and distribution. Curr Opin Chem Biol 6(2):171-180. https://doi.org/10. 1016/S1367-5931(02)00298-3

Qin JJ, Li RQ, Raes J, Arumugam M, Burgdorf KS, Manichanh C, Nielsen T, Pons N, Levenez F, Yamada T, Mende DR, Li JH, Xu JM, Li SC, Li DF, Cao JJ, Wang B, Liang HQ, Zheng HS, Xie YL, Tap J, Lepage P, Bertalan M, Batto JM, Hansen T, Le Paslier D, Linneberg A, Nielsen HB, Pelletier E, Renault P, Sicheritz-Ponten T, Turner K, Zhu HM, Yu C, Li ST, Jian M, Zhou Y, Li YR, Zhang XQ, Li SG, Qin N, Yang HM, Wang J, Brunak S, Dore J, Guarner F, Kristiansen K, Pedersen O, Parkhill J, Weissenbach J, Bork P, Ehrlich SD, Wang J, Consortium M (2010) A human gut microbial gene catalogue established by metagenomic sequencing. Nature 464(7285):59-70. https://doi.org/10.1038/nature08821

Reiff C, Kelly D (2010) Inflammatory bowel disease, gut bacteria and probiotic therapy. Int J Med Microbiol 300(1):25-33. https://doi.org/ 10.1016/j.ijmm.2009.08.004

Scheiber IF, Mercer JF, Dringen R (2014) Metabolism and functions of copper in brain. Prog Neurobiol 116:33-57. https://doi.org/10.1016/ j.pneurobio.2014.01.002

Seiler C, Berendonk TU (2012) Heavy metal driven co-selection of antibiotic resistance in soil and water bodies impacted by agriculture and aquaculture. Front Microbiol 3:399. https://doi.org/10.3389/fmicb. 2012.00399

Shen TJ, Chao A, Lin CF (2003) Predicting the number of new species in further taxonomic sampling. Ecology 84(3):798-804. https:// doi.org/10.1890/0012-9658(2003)084[0798:PTNONS]2.0.CO;2

Sogin ML, Morrison HG, Huber JA, Mark Welch D, Huse SM, Neal PR, Arrieta JM, Herndl GJ (2006) Microbial diversity in the deep sea and the underexplored "rare biosphere". Proc Natl Acad Sci USA 103(32):12115-12120. https://doi.org/10.1073/pnas.0605127103 
Song J, Y1 L, Ch H (2013) Effects of copper-exchanged montmorillonite, as alternative to antibiotic, on diarrhea, intestinal permeability and proinflammatory cytokine of weanling pigs. Appl Clay Sci 77-78: 52-55. https://doi.org/10.1016/j.clay.2013.01.016

Sonnenburg JL, Angenent LT, Gordon JI (2004) Getting a grip on things: how do communities of bacterial symbionts become established in our intestine? Nat Immunol 5(6):569-573. https://doi.org/10.1038/ ni1079

Soumeh EA, Van Milgen J, Sloth NM, Corrent E, Poulsen HD, Norgaard JV (2015) The optimum ratio of standardized ileal digestible leucine to lysine for 8 to $12 \mathrm{~kg}$ female pigs. J Anim Sci 93(5):2218-2224. https://doi.org/10.2527/jas.2014-8699

Southern LL, Adeola O, Lange CMD, Hill GM, Kerr BJ, Lindemann MD, Miller PS, Odle J, Stein HH, Trottier NL (2012a) Carbohydrates. In: Whitacre PT (ed) Nutrient requirements of swine. 11th edn. The National Academies Press, Washington, D.C., pp 58-65

Southern LL, Adeola O, Lange CMD, Hill GM, Kerr BJ, Lindemann MD, Miller PS, Odle J, Stein HH, Trottier NL (2012b) Nutrient requirments tables. In: Whitacre PT (ed) Nutrient Requirements of Swine. 11th edn. The National Academies Press, Washington, D.C., p 226

Sun Y, Su Y, Zhu W (2016) Microbiome-metabolome responses in the cecum and colon of pig to a high resistant starch diet. Front Microbiol 7:779. https://doi.org/10.3389/fmicb.2016.00779

Takaya Y, Yoshihara F, Yokoyama H, Kanzaki H, Kitakaze M, Goto Y, Anzai T, Yasuda S, Ogawa H, Kawano Y (2015) Risk stratification of acute kidney injury using the blood urea nitrogen/creatinine ratio in patients with acute decompensated heart failure. Circ J 79(7): 1520-1525. https://doi.org/10.1253/circj.CJ-14-1360

Tsukahara T, Ushida K (2001) Organic acid profiles in feces of pigs with pathogenic or non-pathogenic diarrhea. J Vet Med Sci 63(12):13511354. https://doi.org/10.1292/jvms.63.1351
Varel VH, Robinson IM, Pond WG (1987) Effect of dietary copper sulfate, aureo SP250, or clinoptilolite on ureolytic bacteria found in the pig large intestine. Appl Environ Microbiol 53(9):2009-2012

Veum TL, Carlson MS, Wu CW, Bollinger DW, Ellersieck MR (2004) Copper proteinate in weanling pig diets for enhancing growth performance and reducing fecal copper excretion compared with copper sulfate. J Anim Sci 82(4):1062-1070. https://doi.org/10.2527/ 2004.8241062x

Wang MQ, Du YJ, Wang C, Tao WJ, He YD, Li H (2012) Effects of copper-loaded chitosan nanoparticles on intestinal microflora and morphology in weaned piglets. Biol Trace Elem Res 149(2):184 189. https://doi.org/10.1007/s12011-012-9410-0

Xia MS, Hu CH, Xu ZR (2005) Effects of copper bearing montmorillonite on the growth performance, intestinal microflora and morphology of weanling pigs. Anim Feed Sci Technol 118(3-4):307-317. https://doi.org/10.1016/j.anifeedsci.2004.11.008

Xia J, Psychogios N, Young N, Wishart DS (2009) MetaboAnalyst: a web server for metabolomic data analysis and interpretation. Nucleic Acids Res 37(Web Server issue):652-660. https://doi.org/10.1093/ nar/gkp356

Zhang F, Zheng WJ, Guo R, Yao W (2017a) Effect of dietary copper level on the gut microbiota and its correlation with serum inflammatory cytokines in Sprague-Dawley rats. J Microbiol 55(9):694-702. https://doi.org/10.1007/s12275-017-6627-9

Zhang SH, Zeng XF, Ren M, Mao XB, Qiao SY (2017b) Novel metabolic and physiological functions of branched chain amino acids: a review. J Anim Sci Biotechno 8:10. https://doi.org/10.1186/s40104016-0139-z

Zhou W, Kornegay ET, van Laar H, Swinkels JW, Wong EA, Lindemann MD (1994) The role of feed consumption and feed efficiency in copper-stimulated growth. J Anim Sci 72(9):2385-2394 